Document downloaded from:

http://hdl.handle.net/10251/154026

This paper must be cited as:

Serrano, J.; Arnau Martínez, FJ.; García-Cuevas González, LM.; Samala, V.; Smith, L. (2019). Experimental approach for the characterization and performance analysis of twin entry radial-inflow turbines in a gas stand and with different flow admission conditions. Applied Thermal Engineering. 159:1-14.

https://doi.org/10.1016/j.applthermaleng.2019.113737

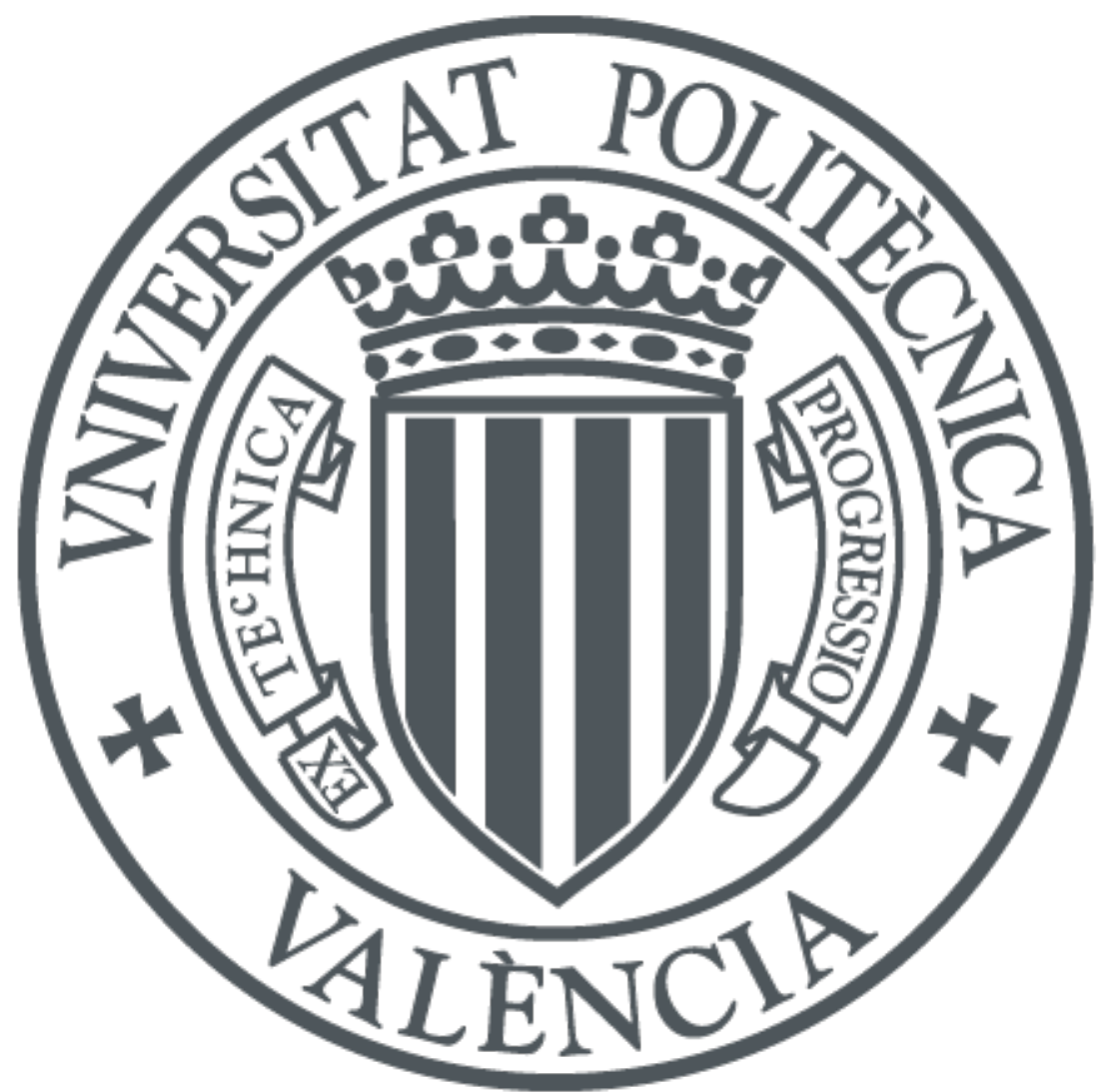

The final publication is available at

https://doi.org/10.1016/j.applthermaleng.2019.113737

Copyright Elsevier

Additional Information 


\title{
Experimental approach for the characterization and performance analysis of twin entry radial-inflow turbines in a gas stand and with different flow admission conditions
}

\author{
José Ramón Serrano ${ }^{\mathrm{a}}$, Francisco J. Arnau, ${ }^{\mathrm{a}, *}$, Luis Miguel Gracía-Cuevas ${ }^{\mathrm{a}}$, \\ Vishnu Samala ${ }^{\mathrm{a}}$, Les Smith ${ }^{\mathrm{b}}$ \\ ${ }^{a}$ CMT-Motores Térmicos, Universitat Politècnica de València, Camino de Vera s/n. \\ 46022 València, Spain \\ ${ }^{b}$ Jaguar Land Rover Ltd, Abbey Road, Whitley, CV3 4LF Coventry, UK
}

\begin{abstract}
In an internal combustion engine, twin entry turbine operates under different unequal admission conditions by feeding the turbine with a dissimilar amount of flow in each entry for a majority of the time. Despite of the impact on turbine performance, normal characteristic maps of these turbines are usually available only for full admission conditions. The current study investigates the best way of building characteristic maps of twin entry radial inflow turbines working under different admission conditions. The mass flow conditions are varied independently for each entry and results are examined to characterize the turbine performance parameters. The new methodology provides a practical approach regarding the reduced turbine speed; mass flow ratio; pressure ratios and efficiencies of a twin entry turbine. The most im-
\end{abstract}

\footnotetext{
*Corresponding author. Tel: +34963877650; fax: +34963877659

Email address: farnau@mot.upv.es (Francisco J. Arnau)

$U R L$ : www.cmt.upv.es (Francisco J. Arnau)
} 
portant conclusion of this work is the protocol of data analysis itself, which allows systematizing the testing procedure of this type of turbines with different steady flow admission and in quasi-adiabatic conditions. By sorting the experimental data in an orderly manner through proposed analysis, the readers can get benefit of this procedure to calibrate their own quasi-steady models for both: mass flow rate and efficiency; or to build new quasi-steady models with clear merit functions for fitting.

Keywords:

Turbocharger, Twin-entry radial turbine, Unequal admission conditions, Performance characteristics, Quasi-steady state 


\section{Nomenclature}

BEVs Battery Electric Vehicles (-)

BSR Blade to jet Speed Ratio (-)

$c_{p} \quad$ Specific heat capacity $\left(\mathrm{J} \mathrm{kg}^{-1} \mathrm{~K}^{-1}\right)$

EGR Exhaust Gas Recirculation (-)

ETE Effective Turbine Efficiency (-)

ILS Independent Lubrication System (-)

MFP Mass Flow Parameter (-)

MFR Mass Flow Ratio (-)

$\dot{m} \quad$ Mass flow $\left(\mathrm{kg} \mathrm{s}^{-1}\right)$

$N \quad$ Rotational speed (rpm)

$p \quad$ Pressure $(\mathrm{Pa})$

$T \quad$ Temperature (K)

$\dot{W} \quad$ Power $(\mathrm{W})$ 


$\begin{array}{ll}\text { Superscript } \\ \text { avg } & \text { Average } \\ c & \text { Compressor } \\ H & \text { Hub } \\ S h & \text { Shroud } \\ t & \text { Turbine } \\ T E & \text { Twin Entry }\end{array}$

Subscript

01 Compressor inlet total conditions

02 Compressor outlet total conditions

03 Turbine inlet total conditions

04 Turbine outlet total conditions

$4 s \quad$ Turbine outlet static conditions

$t / s \quad$ Total to static

Tisen Turbine isentropic

T Turbine

C Compressor

m Mechanical 


\section{Greek letters}

$\gamma$ Heat capacity ratio

$\eta \quad$ Corresponding efficiency

$\pi \quad$ Corresponding pressure ratio

$\sigma$ Corresponding blade to jet speed ratio 


\section{Introduction}

On the one hand, improving the performance of vehicle engines, like to control the gaseous emissions [1]; combustion and exhaust noise [2, 3] as well as reducing the fuel consumption, while meeting future real driving emission regulation, has become a key target for the automotive propulsion system engineers. On the other hand, the future of internal combustion engines will be alive and healthy until at least 2050 according to recent studies [4] and since nowadays BEVs have a heavy $\mathrm{CO} 2$ footprint when analyzed from cradle to grave $[5,6]$. It is expected that plug-in hybrid powertrains and small capacity turbocharged engines will be covering the major part of the powertrain demands for passenger cars in decades ahead. [7]. Nowadays, the demand for turbochargers in light duty trucks and passenger cars are increasing significantly. The modern turbocharging concepts have advantages of low fuel consumption and emission reduction with high specific rated engine power [8]. However, concerning future legal requirements for low emissions (Euro 6 and Euro 7 regulations) with fuel efficiency, there is still need and potential for optimization, of a number of nowadays technologies like: variable geometry turbine, two-stage turbocharging and asymmetric/symmetric twin-entry turbine used for improving engine performance. Among such technologies, twin-entry turbocharger nowadays become one of the lead components for four cylinders turbocharged petrol engines with wide valves overlap period in their timing diagram or 6 cylinder compression ignition engines. It has the advantages of utilizing the pulse energy coming from the engine exhaust and minimizing the interferences between cylinders during exhaust process (engine pumping losses). In six-cylinder truck engines also asymmetric twin 
entry turbines are of interest in order to produce EGR only with the bank of cylinders connected to the smaller cross-section entry and therefore with the higher back pressure [9]. Numerous researchers have reported that the engine exhaust pulsatile flows significantly influence the turbine performance of a twin turbine powered turbocharger $[10,11,12]$. In almost every engine operating condition, there is an imbalance of flow conditions between the two entries of a twin entry radial inflow turbine. The staggered firing order of the engine cylinders also leads to dissimilar inlet pressure and temperature levels in the twin entries, this is known as unequal admission. However, one should note that the partial admission condition, i.e., zero flow in one of the branches, is not viable to appear under conventional engine operating conditions.

Twin-entry turbine design first appeared in 1954 [10], and it has neither complex control systems nor mechanical structure as compared with variable geometry turbine and two-stage turbocharging. Pischinger and Wunsche [13] were the first researchers who investigated the flow characteristics and the efficiencies of the radial twin-entry turbine in comparison with dual volute turbine, under the steady flow at partial and full admission conditions. The conclusions of their studies pointed that the efficiency losses at partial admission conditions are significant, but it mainly depends upon the turbine speed and pressure levels. They further concluded that twin-entry turbines have better efficiency when the flow conditions are same in both turbine branches. Dale and Watson [14] continued the work done by the Pischinger and Wunsche [13] on the twin-entry turbine by testing it with both equal and unequal admission. The effect of unequal admission on turbine perfor- 
mance was such that the best efficiency was found when the mass flow rate is higher in shroud side entry than in hub entry. Further indicated that the efficiency varies with different unequal admission conditions. The same outcome was moreover presented later by Capobianco and Gambarotto [15] and also investigated by comparing the single-entry to a twin-entry turbine, and noticed that the efficiency of the twin-entry turbine is around $7 \%$ less under full admission conditions. Baines and Lavy [16], Baines et al. [17] directly measured the performance and the flow field of the vaneless twin-entry radial turbine under partial and full admission conditions. The result of their works attested that under unequal admission conditions, the variation of flow velocity is much higher in the spanwise direction. They also found that the flow angle is unaffected by changes in turbine operating conditions under same admission flow at the turbine inlet. In partial admission cases (i.e., when one entry is blanked off), a strong indication of flow recirculation was reported from one entry to another, in result there was a substantial efficiency penalty. Hajilouy-Benisi et al. [18] presented a numerical and experimental investigation of the performance and internal flow field characteristics of twin-entry radial inflow turbine at full and partial admission conditions. The experimental performance results showed that maximum efficiency occurs at equal admission conditions for the considered range and the lowest efficiency are obtained when the entire flow is in the hub side branch.

Romagnoli et al. [19] reported the performance results obtained for three different turbine configurations. The turbine which was tested in their study was based on the existing nozzles commercial turbine, and it was modified into a variable geometry single-entry turbine and twin-entry turbine. The 
steady-state experiments conducted on twin entry turbine under full admission at vane angle of $60^{\circ}$ showed that the influence of the divider is not essential concerning efficiency. However, at a vane angle between $40^{\circ}$ and $50^{\circ}$, a notable drop in efficiency was reported. Rajoo et al. [20] discussed the performance of the same modified twin-entry turbine examined under unsteady flow situations and concluded that the swallowing capacity during full admission was varying between the two entries. The shroud side branch was more pressurized than the hub side branch. Chiong et al. [21] studied the accuracy of pulse flow model prediction and pointed out that, partial admission performance should consider during model characterization to have a significant pulse flow prediction quality. They further concluded that twin entry turbine is operating at unequal admission mode instead of full admission mode throughout the in-phase pulse flow conditions they tested.

Several publications went into detail about the benefits and drawbacks of twin entry turbine working under full, partial and unequal admission conditions. However, from the literature, there is no clear information about how to assess the characteristic maps of the turbine that give particular information at different admission conditions. Also, the knowledge of twin entry turbine behavior is still inadequate leading to an unsatisfactory performance prediction with the tools available. This is due to the lack of understanding the flow similarity of the twin entry turbine. Accordingly, the current investigation is motivated by two perspectives. First, a way of measuring the performance data needed under different admission conditions to further characterize the mass flow and efficiency parameters. Secondly, providing a way of computing the turbine performance parameters so that the flow 
behavior can be explained. Another objective, to be fully developed in future works, is that proposed methodology allows managing the measured data with the current turbine models for further extrapolation and gaining a better matching between the turbocharger and the engine.

The turbocharger used in this work is a twin entry symmetrical radial in-flow turbine with a waste-gate and for applications in an automotive commercial gasoline engine. Before proceeding further, it is necessary to provide some clarification to the readers about the labeling utilized in this paper to recognize the entries of a twin-entry turbine as shown in Figure 1. The turbine scroll has a single wall around the entire perimeter of the turbine housing such that each entry admits the exhaust gas over the whole circumference of the turbine wheel. The entry closer to the turbine outlet is named as Shroud, and the entry which is closer to the bearing housing side is called Hub, and the same is shown in Figure 1. From now on, the turbine entries are referred to the named ones.
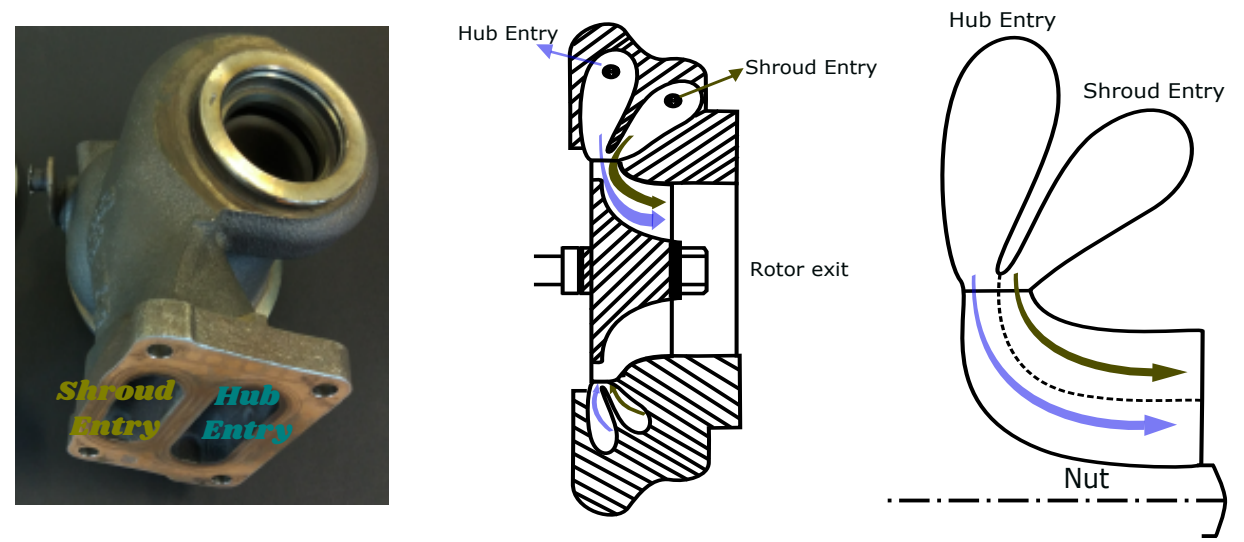

Figure 1: Sketch of twin entry turbine for the investigation 


\section{Experimental Method}

\subsection{Turbocharger Gas Stand}

The experimental activity is carried out in a turbocharger test facility located at 'CMT-Motores Térmicos'. The tests of twin entry turbine usually contain measurements of both turbine inlets with full admission conditions, and also measurements of each turbine inlet while the other inlet held closed. This kind of tests can be performed on a test bench designed for single entry turbines, named standard test bench. However, in turbine tests at full admission conditions can be measured only the total mass flow. Therefore, the mass flow distribution between the individual turbine entries is both uncontrolled and unknown under full admission conditions. For these reasons, the available turbocharger test rig has been modified to investigate the twin entry/ dual volute turbocharger under a variety of operational conditions based on the flow simulation of a turbocharger using compressed air. The main features are the possibility of generating cold or hot flow in the turbine at different flow admission requirements. As shown in Figure 2, the gas after combustion chamber split into two independent sets of pipe-work which are ideally suited to twin entry turbines. The mass flow rate in shroud and hub is controlled independently through two control valves, thus allowing to test the turbocharger with different steady flow admission conditions. There is also a possibility of changing the outlet conditions of the compressor using back-pressure valves. Sensors to measure the parameters like turbocharger

speed, pressure, temperature, and mass flow at the essential sections of the various fluids are also available. Main characteristics of the turbocharger test facility are listed below. 
- As a gas-supplier, a two-stage centrifugal compressor is used. This compressor type is oil-free and has an air cooler at downstream, and powered by a $450-\mathrm{kW}$ electric motor. The maximum relative pressure of 5.30 bar can be reached, and the disposing capacities range between $4400-7200 \mathrm{Nm} 3 / \mathrm{h}$. There is one settling tank on the line between compressor and combustion chamber and also three bleeding valves for evacuation of excess air to ambient.

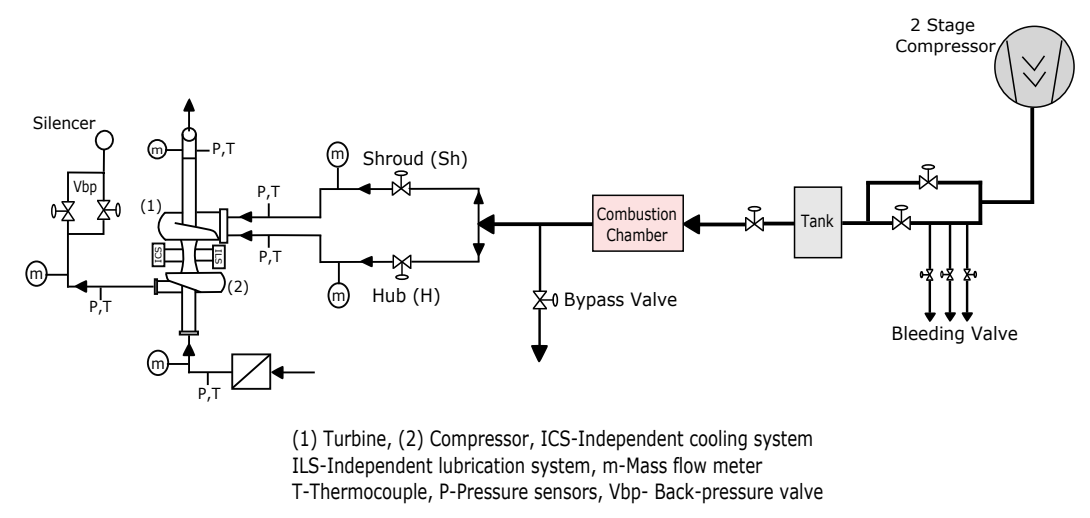

Figure 2: Schematic test bench layout and location of main sensors

- A combustion chamber heats the mass flow that is fueled by diesel oil. This system can increase the temperature of mass flow to a maximum of $1200 \mathrm{~K}$. The combustion chamber is not operated as the tests were carried out in quasi-adiabatic conditions at a turbine inlet temperature around $363 \mathrm{~K}$. This temperature is achieved by just using the two-stage centrifugal compressor and then it is the only one that controls the amount of energy available at the turbine.

- Downstream of the combustion chamber, the flow is divided into the 
two turbine branches as shown in Figure 3b, where new measurements of mass flow are obtained by means of V-cone type sensors. Two control valves are placed at upstream of the turbine inlets to control flow going into each of the branches.

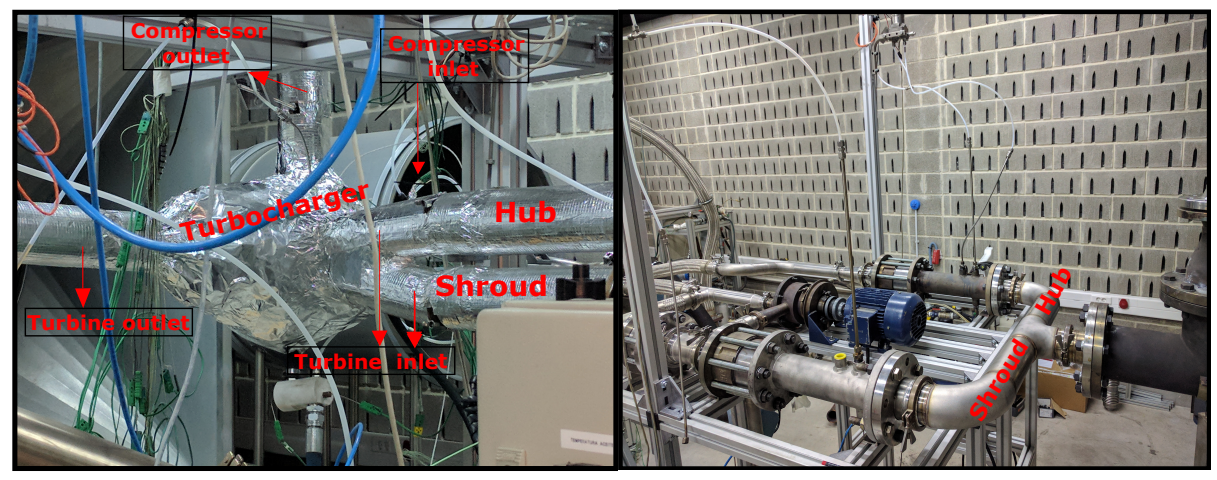

(a) Turbocharger with insulation

(b) Flow separation and controlling section

Figure 3: Turbocharger setup in the gas stand

- At the downstream of turbine, a third V-cone sensor is installed for measuring the total mass flow exiting from the turbine.

- The compressor of the turbocharger takes air from the ambient and passes through a filter and then by a hot-plate flow meter to measure the flow. At the downstream side of the compressor, there is a mass flow meter of vortex type and also an electronic control back-pressure valve which can modify the pressure ratio of the compressor, i.e., to move from surge to choke conditions of the compressor.

- An independent lubricating system (ILS) is used to deliver oil at an adjustable flow rate, temperature and pressure. This system includes a 
heater and cooler that give the option to adjust the temperature at turbocharger inlet lube port. A Coriolis-type flow meter is used to measure the oil mass flow and low uncertainty platinum resistance temperature detectors are used for inlet and outlet temperatures measurement.

- Temperature and pressure sensors are installed on the inlet, and outlet pipes of the turbine and compressor; according to the guidelines of SAE international [22], [23] turbocharger gas stand measurement and their precision is shown in Table 1.

- Inlet and outlet pipes of the turbine and compressor were insulated including the complete turbocharger (see Figure 3a); to make sure heat losses to the ambient are negligible and ensure more adiabatic operation of the turbocharger.

\begin{tabular}{|c|c|c|c|}
\hline Variable & Sensor Type & Range & Typical uncertainty \\
\hline Gas mass flow & $\begin{array}{c}\text { V-cone and } \\
\text { Thermal vortex }\end{array}$ & $45-1230 \mathrm{~kg} / \mathrm{hr}$ & $\begin{array}{c}<1 \% \text { of the } \\
\text { measured values }\end{array}$ \\
\hline Gas pressure & Piezoelectric & 0 to $5 \mathrm{bar}$ & $12.5 \mathrm{mbar}$ \\
\hline $\begin{array}{c}\text { Gas } / \text { metal } \\
\text { temperature }\end{array}$ & $\begin{array}{c}\text { K-type } \\
\text { thermocouple }\end{array}$ & $273 \mathrm{~K}$ to $1500 \mathrm{~K}$ & $1.5 \mathrm{~K}$ \\
\hline Oil pressure & Piezoelectric & 0 to $5 \mathrm{bar}$ & $12.5 \mathrm{mbar}$ \\
\hline Oil temperature & RTD & $173 \mathrm{~K}$ to $723 \mathrm{~K}$ & $<0.5 \mathrm{~K}$ \\
\hline Oil mass flow & Coriolis & Few tens gr $/ \mathrm{s}$ & $2 \%$ of the \\
measured value
\end{tabular}

Table 1: Gas stand measurement equipments and their precision 


\subsection{Test Methodology}

One of the main issues concerning the investigation of twin entry turbine is that of assessing the impact of each entry on the overall performance in steady flow under varying flow admission conditions. The operating behavior of twin entry turbines under the pulsating admission of the combustion engine can be divided into flow conditions. Brinkert et al. [24] indicate that testing the twin entry turbines with the scroll pressure ratio as only control parameter cannot guarantee equal flow conditions along one turbine speed line unless they are entirely symmetrical. Consequently, turbine considered here was investigated under a range of different turbocharger speeds with varying mass flow conditions in shroud and hub branches. The flow rate at each entry of the turbine was controlled by the two control valves as shown in Figure 2. Table 2 reported the test conditions showing the flow rates between inlets. These conditions are further divided into three different categories as follows:

- Full/equal admission: This operation is possible to measure on the gas stand and occurs when each entry of the turbine is provided the same mass flow rate.

- Partial admission: This occurs when flow passes through one turbine entry only. It is performed on the gas stand by blocking one of the inlets and employing the flow into open inlet and vice versa.

- Unequal admission: In the middle of two limits of full and partial admission cases it is possible to measure the turbine with different admission points. These are the cases in an engine; twin entry turbocharger 
operates by feeding the turbine with an unequal amount of flow in each entry.

For a distinctive allocation of a flow condition to the corresponding turbine characteristic, mass flow ratio definition has been used [25], [26]. It is defined according to Equation 1, as the mass flow rate in the shroud branch divided by the overall mass flow rate of the turbine.

$$
M F R=\frac{\dot{m}_{S h}}{\dot{m}_{S h}+\dot{m}_{H}}
$$

The above said admissions can be defined by Equation 1. As a result of being able to measure these different flow admission conditions, a flow interactive map can be created as presented in Figure 4. The flow interaction map shows the experimental turbine operating conditions corresponding to extreme situations for each entry; partial admission (MFR 1 and 0), and further equal and unequal mass flow in shroud and hub branches (MFR 0.5, $0.43,0.8, .$.$) . The flow conditions of Table 2$ are all marked in Figure 4. 


\begin{tabular}{|c|c|c|}
\hline \multirow{3}{*}{ MFR } & \multicolumn{2}{|c|}{ Flow Split Rate } \\
\cline { 2 - 3 } & Sh/H & H/H \\
\hline 0 & 0.00 & 1.00 \\
\hline 0.2 & 0.25 & 1.00 \\
\hline 0.31 & 0.50 & 1.00 \\
\hline 0.43 & 0.75 & 1.00 \\
\hline \multirow{2}{*}{ MFR } & Flow Split Rate \\
\cline { 2 - 3 } & Sh/Sh & H/Sh \\
\hline 0.53 & 1.00 & 0.89 \\
\hline 0.57 & 1.00 & 0.75 \\
\hline 0.67 & 1.00 & 0.50 \\
\hline 0.8 & 1.00 & 0.25 \\
\hline 1 & 1.00 & 0.00 \\
\hline
\end{tabular}

Table 2: Turbine inlet flow conditions. Every MFR at every turbocharger speed has been measured with similar total flow when adding flow through both branches. 


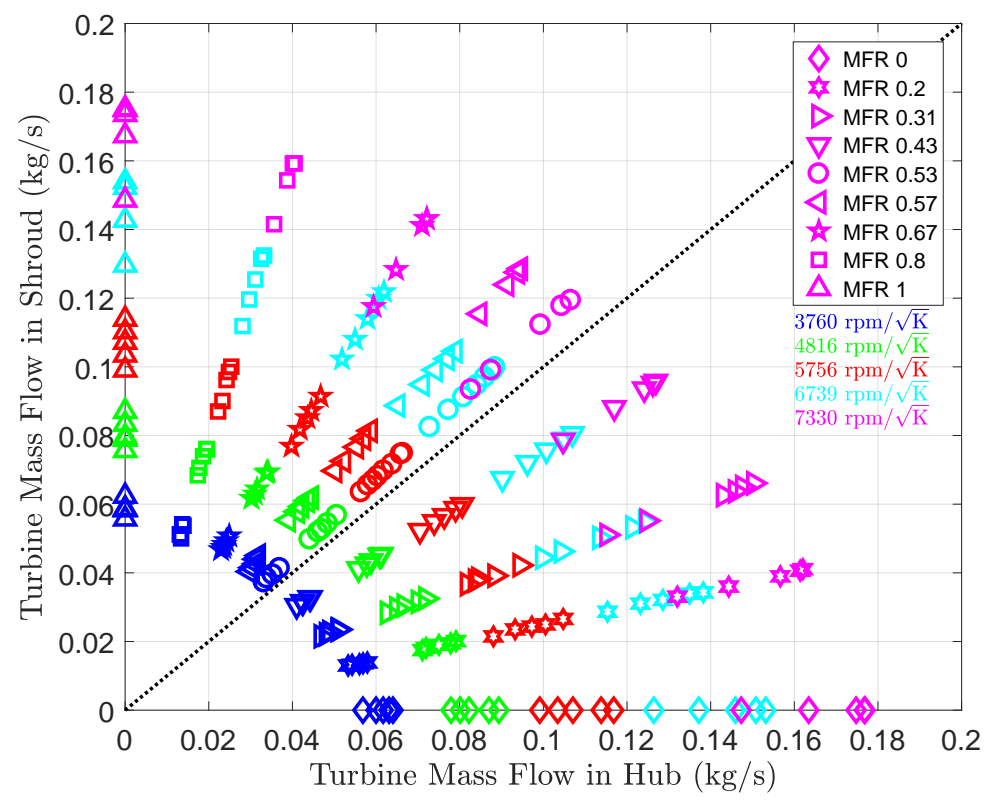

Figure 4: Turbine inlet flow interaction map

Figure 5 shows the relation between scroll pressure ratio shroud-to-hub and mass flow ratio (MFR) for different flow admission conditions with turbine reduced speed. For a particular mass flow ratio between zero and unity, the flow conditions in shroud and hub branch remain equal, i.e., at MFR 0.5 where the turbine works under full admission conditions, and the resulting scroll pressure ratio will be equal to unity and which can be seen in Figure 5. Thus, concludes that the turbocharger tested in the gas stand is twin entry symmetric turbine and have a similar flow capacity in two entries. In our experiments, the position of two control valves at upstream of the turbine inlets are controlled by sending a signal from a computer and which is fixed during the entire test. While measuring the full admission condition, the position of control valve at the hub side branch has not been able to control 
exactly $\mathrm{MFR}=0.5$. For this reason, the test was completed at MFR 0.53, which is very close to MFR 0.5 (showed in dotted lines in Figure 5). Moreover, the scroll pressure ratio is also almost close to unity. From Figure 5, it can be also noted that for an individual flow admission condition the mass flow ratio is held constant for all measured turbocharger speeds. Also, can be checked that as Brinkert et al. [24] indicates the scroll pressure ratio changes for same MFR as a function of the reduced speed of the turbine and trend is inverted between MFR 0 and 1 . Only at MFR 0.5, the scroll pressure ratio is constant, and equal to one, for all reduced speeds.

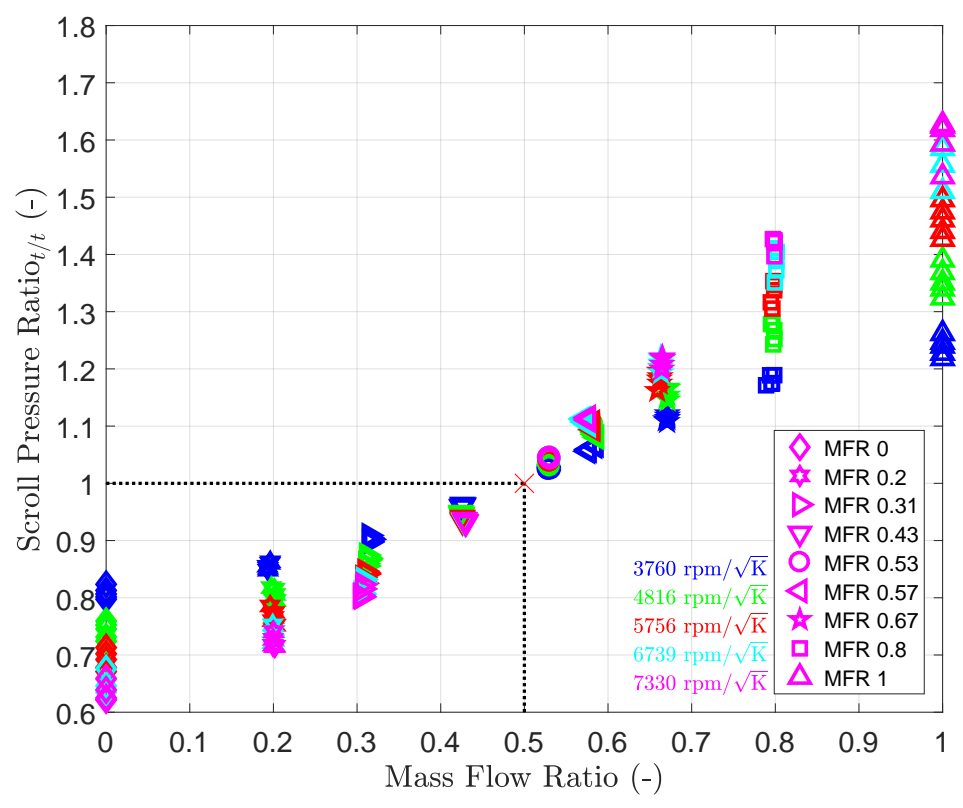

Figure 5: Turbine scroll pressure ratio with mass flow ratio

Figure 6 and Figure 7 show the mass flow balance of the turbine and compressor for different mass flow ratios that carried out in a gas stand. From Figure 6 it is clear that the total amount of mass given to the turbine in each 
different admission conditions are similar and as a result, the corrected speed of the compressor should not be different. Both figures further conclude that there are no relevant leaks of flow from measurement pipes as the flow rate is balanced from inlet to outlet of the turbine and compressor and also within the measurement difference of $\pm 3 \%$.

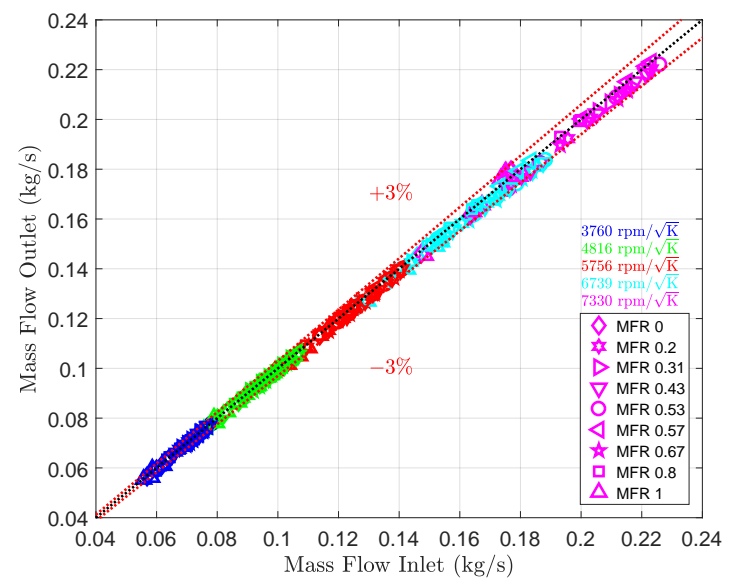

Figure 6: Mass flow balance of the turbine

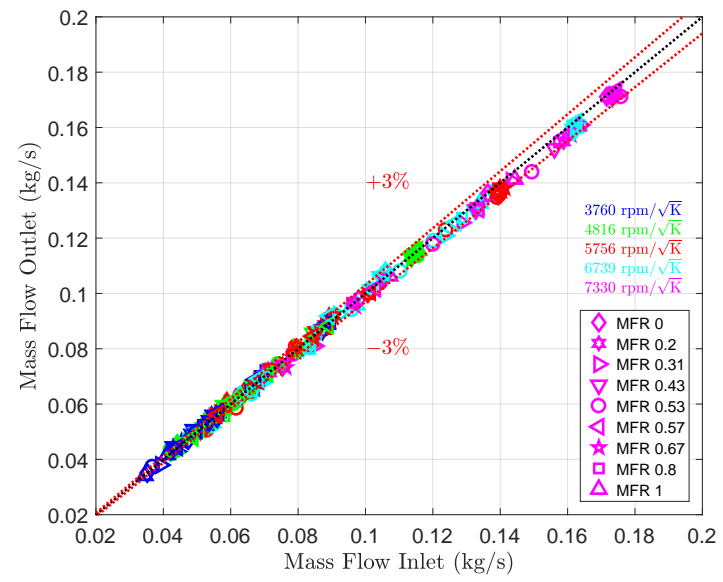

Figure 7: Mass flow balance of the compressor 
The measurements with different mass flow ratios at the turbine inlets are performed from $68 \mathrm{krpm}$ to $136 \mathrm{krpm}$ in steps of $18 \mathrm{krpm}$ in compressor corrected speed, and in between surge and choke conditions of it, as shown in Figure 8. The total inlet mass flow rate to the turbine in each different admission conditions is changed accordingly in order to obtain as a result that, the corrected speed and operating conditions of the compressor are the same in all turbine inlet admission cases.

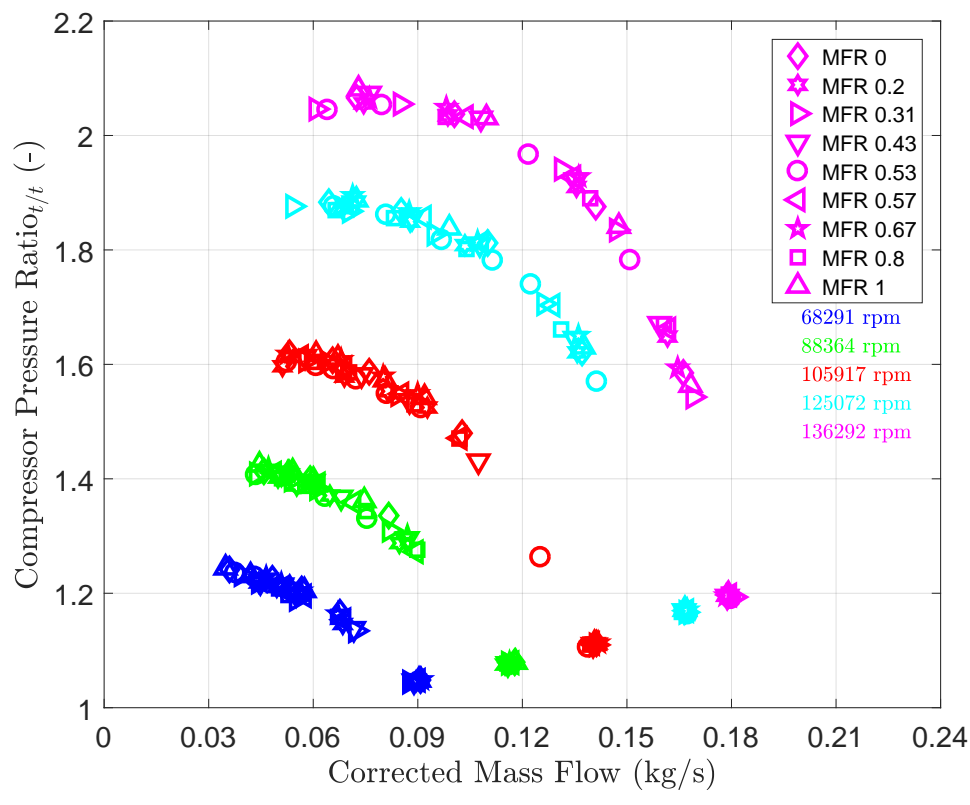

Figure 8: Compressor map in all admission cases

The procedure for testing the turbocharger at quasi-adiabatic conditions us by providing the lowest possible temperature gradients between its elements and also by minimizing the heat transfer internally and externally. Zimmermann et al. [27], assert that despite the significant insulation and controlling the temperatures, still remains a minor internal and external heat 
transfer. These minor heat losses are more significant at lower turbo speeds than at higher turbo speeds; even with the quasi-adiabatic tests. Similar was observed in our experiments at lower turbo speeds and it is represented in the Figure 9 as raw data processing (orange lines represents the different MFR data). At high speeds, the heat transfer effects on the compressor outlet temperature are almost negligible in comparison to mechanical power. Therefore, a heat transfer correction suggested by Zimmermann et al. [27] is applied only to first three lower speeds to obtain fully adiabatic results, and rest are considered to be adiabatic enough with a relative unbalance of $\pm 3 \%$ at higher speed as can be deducted from Figure 10. To determine whether the measurement is sufficiently adiabatic the idea behind their methodology was based on the power-based criterion. The approach is to identify a relatively constant heat transfer rate with the turbocharger speed; for this, a total turbine enthalpy drop is represented against the isentropic compressor power. Considering the points of a maximum isentropic compressor power for each speed line, they fits into a straight line. By considering that all the turbine power is used to be converted into compressor power, and when the required compressor power reaches to zero (i.e., at zero speed), the turbine power has to be down to zero as well. This indicates the almost adiabatic measurements. Every deviation from zero at the axis ordinates are affected by heat flows [27]. The same kind of approach is carried out on the measurement values of the compressor, but by representing the effective compressor power against the isentropic compressor power.

Figure 9 presents the energy balance of turbocharger for different said admission conditions. Here the energy input is the power provided to the 
turbine and energy output is the summation of powers generated by the compressor and mechanical losses. In quasi-adiabatic tests, the energy absorbed by the lubrication oil will mainly come from the heat generated by the friction; therefore, the mechanical losses are estimated by enthalpy difference in oil and its mass flow and specific heat capacity. From Figure 9, it is evident that the lower speeds were perfectly balanced after the correction of minor heat losses (showed with different symbols for mentioned flow admission conditions). The error of energy balance is in between $\pm 0.5 \mathrm{~kW}$ from lower to higher turbocharger speeds. By assessing the overall energy balance of the turbocharger shows the significance of work transfer from the turbine to a compressor and also signifies the accuracy of adiabatic efficiency calculations; as it is dependent on the ratio of isentropic enthalpy difference to the measured enthalpy difference between the inlet and outlet stations of the turbine and compressor.

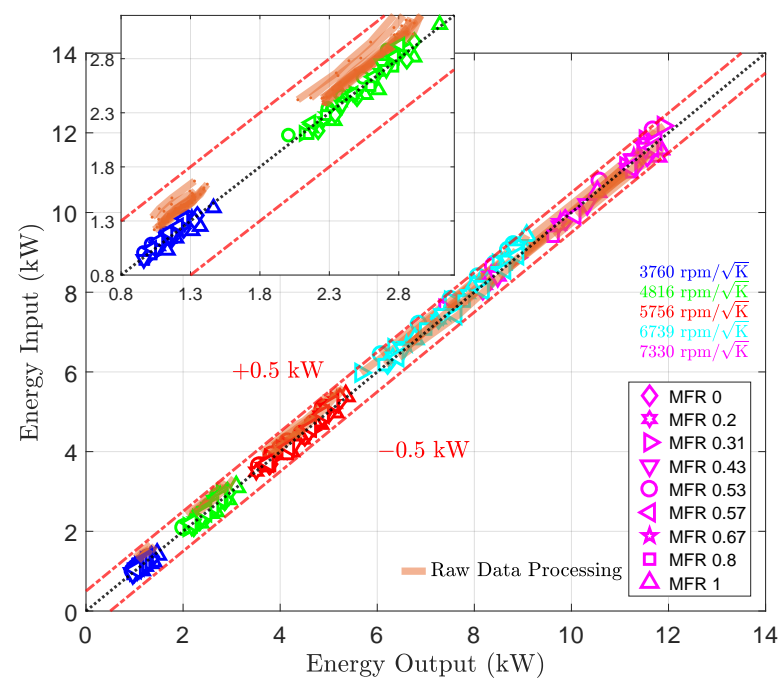

Figure 9: Turbocharger energy balance in all admission conditions 


\subsection{Uncertainty of the Performance Parameters}

The uncertainty of the performance parameters was computed using the standard procedure described in [28] and applied in [29]. The mean and maximum values are presented in Table 3 .

\begin{tabular}{|c|c|c|c|}
\hline Parameter & Average value & Maximum value & Units \\
\hline \multicolumn{4}{|c|}{ Turbine } \\
\hline Mass flow ratio & 0.0017 & 0.0054 & - \\
\hline$\dot{m}_{r e d}($ total $)$ & $4.88 \times 10^{-8}$ & $8.94 \times 10^{-8}$ & $\mathrm{~ms} \mathrm{~K}^{-0.5}$ \\
\hline$\dot{m}_{\text {red }}($ per branch $)$ & $3.45 \times 10^{-8}$ & $6.32 \times 10^{-8}$ & $\mathrm{~ms} \mathrm{~K}^{-0.5}$ \\
\hline Expansion ratio & 0.015 & 0.023 & - \\
\hline$\eta_{t / s}$ & 0.020 & 0.049 & - \\
\hline$\eta_{E T E}$ & 0.015 & 0.035 & - \\
\hline$\sigma$ & 0.006 & 0.022 & - \\
\hline Power & 95 & 216 & $\mathrm{~W}$ \\
\hline \multicolumn{4}{|c|}{ Compressor } \\
\hline Corrected flow & 0.885 & 1.686 & $\mathrm{~g} \mathrm{~s}^{-1}$ \\
\hline Pressure ratio & 0.008 & 0.009 & - \\
\hline Power & 95 & 290 & W \\
\hline
\end{tabular}

Table 3: Uncertainty of the performance parameters 


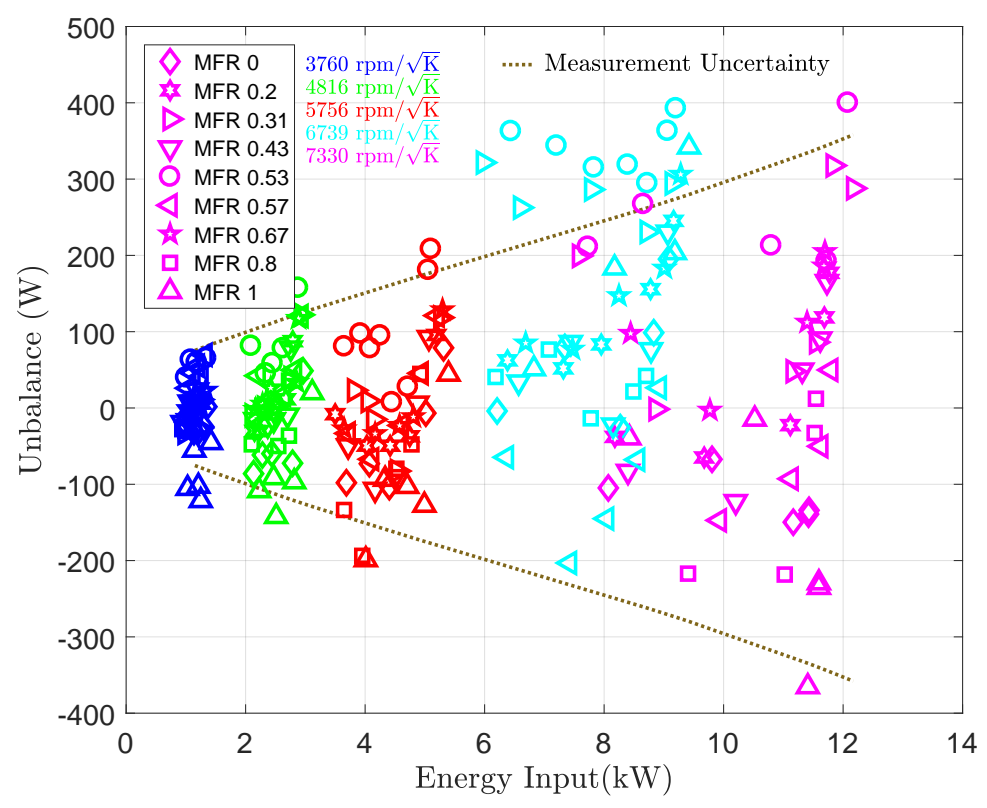

Figure 10: Absolute unbalance in all admission conditions

Figure 10 shows the absolute unbalance for all turbocharger speeds at mentioned flow conditions. It can be concluded that, after the heat transfer correction, the unbalance from lower to higher turbocharger speed is in between $\pm 1 \%$ to $\pm 3 \%$ referred to end of scale tests. The figure also shows the uncertainty of the unbalance and, as it can be seen, the vast majority of the points lies between the experimental uncertainty lines.

\section{Turbine Performance Parameters}

In the following sections, the impact of twin-entry turbine performance parameters in different flow admission conditions is shown. 


\subsection{Flow Performance Map}

\subsubsection{Twin entry turbine as a single turbine}

Literature survey revealed a few publications, where twin entry turbines are tested in different admission conditions. Romagnoli et al. [30] proposed a new definition of mass flow parameter (MFP) to study the twin entry turbines. The MFP is calculated considering the contribution of each entry on the overall flow capacity. Studying twin entry turbine as a single turbine, the flow performance parameters are computed by Romagnoli et al. [30] proposed method as shown in equations 2 and 3 . In this way, all the admission conditions should feature only one turbine flow parameter, representing total flow of the turbocharger turbine. In the case of full and unequal admission conditions, the expansion ratio is calculated as an average value between shroud and hub inlet as shown in equation Equation 4, while for the inlet temperature a mass-weighted average value is considered according to Equa-

tion 5 [30], [31]. For partial admission data, as the flow is only into one of the branches, therefore, the flow parameter and expansion ratio is determined using the conditions of flowing entry only [30]. Figure 11 shows the flow performance of twin entry symmetric turbine for different mass flow ratios with the proposed method. It can be noted that the calculated reduced mass flow parameter is not alike for all flow conditions, mainly significant differences are found between the partial and rest of the admissions. Indeed, the total mass flow given to the turbine during our experiment is $20 \%$ lower in partial admission conditions than in full admission and unequal admission conditions. Nevertheless, full admission and unequal flow conditions have all very similar total flow among them. The same situation happens at partial 
admission conditions, hub and shroud partial admission have both very similar total flow for every turbocharger speed as it is shown in Figure 4. It is clear by observing Figure 6 that, for every turbocharger speed, quite similar total mass flow was delivered to the two inlets of the turbine at full and unequal admission conditions. The expression proposed by Romagnoli et al. [30] does not provides a convergence of the mass flow parameter, but shows a variety of values when used for all the flow admission conditions.

$$
\begin{gathered}
\Pi_{t / s}=\frac{p_{03}^{a v g}}{p_{04}} \\
\dot{m}_{r e d}=\frac{\left(\dot{m}_{S h}+\dot{m}_{H}\right) \cdot \sqrt{T_{03}^{a v g}}}{p_{03}^{a v g}} \\
p_{03}^{a v g}=\frac{p_{03}^{S h}+p_{03}^{H}}{2} \\
T_{03}^{a v g}=M F R \cdot T_{03}^{S h}+(1-M F R) \cdot T_{03}^{H}
\end{gathered}
$$




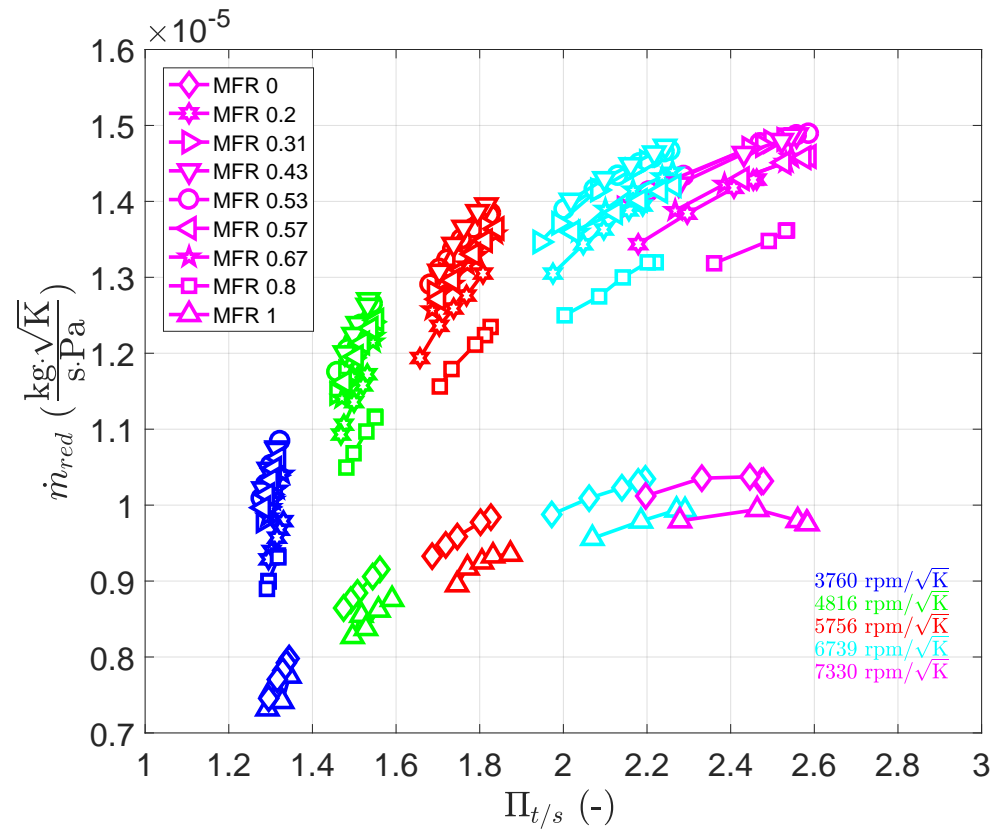

Figure 11: Turbine map considering average inlet parameters

The diversity found in Figure 11 for equal and unequal admission conditions is mainly due to the variation in the shroud and hub inlet temperatures (with ratios from about 0.94 to 1.06) and pressures, as the reduced mass flow parameter is the function of both. These variations are due to different flow situations in the branches. Although this most likely happens when the twin entry turbine works with the engine; as the turbine inlets (shroud and hub) conditions vary due to imbalance of flow coming from the engine [24].

Besides, representing with one turbine flow parameter for both branches with the same mass flow ratio, the mass flow distribution between shroud and hub branches under equal and unequal conditions is therefore not known. Since the knowledge of twin entry turbine performance is still limited, their performance prediction with available tools by using a single map for all the 
flow conditions can lead to undesirable results. Therefore, the overall performance will significantly depend on knowledge about mass flow distribution among the shroud and hub branches.

\subsubsection{Twin entry turbine as two individual turbines}

In twin entry turbocharger, if mass flow entering into each entry of turbine are similar, all of the conventional dimensionless performance parameters such as reduced mass flow, reduced speed, expansion ratio, and blade to jet speed ratio are identical to single-entry turbine [31]. Once the flow conditions between entries vary, standard performance parameters need to be re-evaluated for considering each flow appropriately. Accordingly, assuming each inlet supplies to a separate section of the nozzle, thus using an averaged pressure ratio and temperature to analyze the results of a twin entry turbine is not suitable or meaningful. Therefore, two entries are treated separately by calculating the independent expansion ratio and the mass flow parameter as shown in the equations from (6-9). Note that expansion ratio, reduced speed, blade to jet speed ratio, and reduced mass flow are defined for each shroud and hub separately.

$$
\begin{gathered}
\Pi_{t / s}^{S h}=\frac{p_{03}^{S h}}{p_{04}} \\
\Pi_{t / s}^{H}=\frac{p_{03}^{H}}{p_{04}} \\
\dot{m}_{r e d}^{S h}=\frac{\dot{m}_{S h} \cdot \sqrt{T_{03}^{S h}}}{p_{03}^{S h}}
\end{gathered}
$$




$$
\dot{m}_{r e d}^{H}=\frac{\dot{m}_{H} \cdot \sqrt{T_{03}^{H}}}{p_{03}^{H}}
$$

Figure 12 and 13 show the resulting mass flow parameter of two separate turbines approach for different mass flow admission conditions, i.e., one for shroud and another one for hub. It can be concluded that the turbine measurements show an explicit dependency of flow behavior with mass flow ratio variations. For an increasing mass flow ratio, the turbine flow parameter of the shroud branch increases (as shown in Figure 12) and the hub branch decreases (as shown in Figure 13).

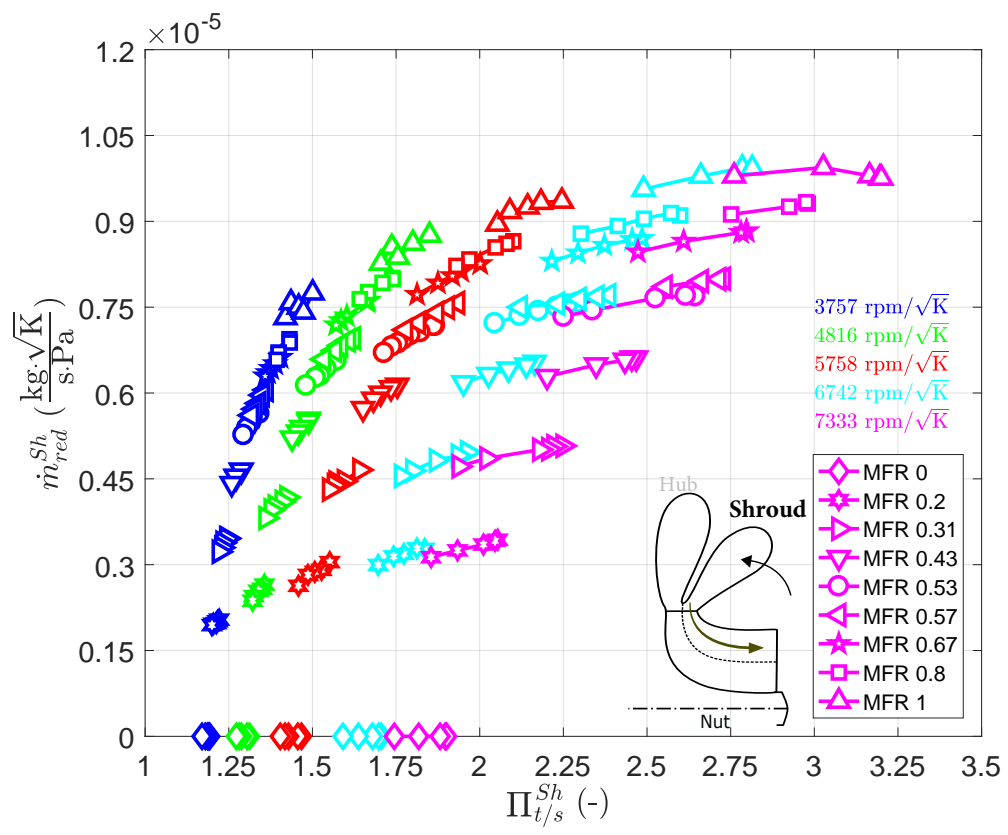

Figure 12: Turbine map for shroud branch 


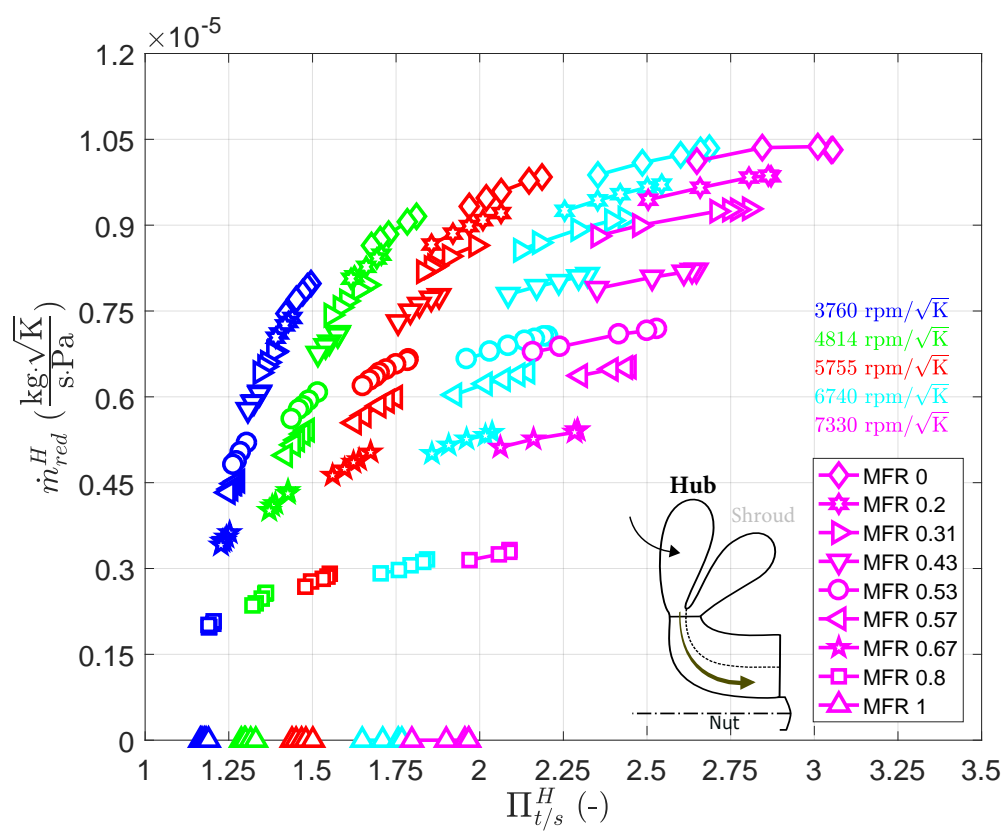

Figure 13: Turbine map for hub branch

Considering shroud and hub inlets as two separate turbines, for every entry the resulting flow parameter at various mass flow ratios show a characteristic similar to single-entry variable geometry turbine (VGT) [32].

\subsection{Efficiency Performance Map}

Based on the fundamental definition of efficiency, the traditional way to calculate the total-static turbine efficiency $\eta_{t / s}$ (which is also called as adiabatic efficiency) is based on the ratio between turbine mechanical power and its isentropic power as shown in Equation 10.

$$
\eta_{t / s}=\frac{\dot{m}_{T} \cdot c_{p}^{t} \cdot\left(T_{03}-T_{04}\right)}{\dot{m}_{T} \cdot c_{p}^{t} \cdot\left(T_{03} \cdot\left(1-\left(1 / \Pi_{t / s}\right)^{(\gamma-1 / \gamma)}\right)\right)}=\frac{\dot{W}_{T}}{\dot{W}_{T, \text { isen }}}
$$


The mechanical efficiency $\eta_{m}$ can be computed by the ratio of compressor power to turbine power as shown in Equation 11.

$$
\eta_{m}=\frac{\dot{m}_{C} \cdot c_{p}^{c} \cdot\left(T_{02}-T_{01}\right)}{\dot{m}_{T} \cdot c_{p}^{t} \cdot\left(T_{03}-T_{04}\right)}=\frac{\dot{W}_{C}}{\dot{W}_{T}}
$$

The product of mechanical efficiency and turbine adiabatic efficiency $\left(\eta_{t / s} \cdot \eta_{m}\right)$ gives the fraction of mechanical compressor power to isentropic turbine power as shown in Equation 12; this ratio is called as effective turbine efficiency (ETE), and it is commonly used by the turbocharger manufacturers to determine the efficiency of the turbine.

$$
\eta_{t / s} \cdot \eta_{m}=\frac{\dot{W}_{T}}{\dot{W}_{\text {Tisen }}} \cdot \frac{\dot{W}_{C}}{\dot{W}_{T}}=\frac{\dot{W}_{C}}{\dot{W}_{\text {Tisen }}}=\eta_{E T E}
$$

In the case of twin entry turbines, calculating the effective turbine efficiency is more apparent by determining the individual isentropic turbine powers of each branch and summed merely, as shown in Equation 13 [33].

$$
\eta_{E T E}=\frac{\dot{m}_{C} \cdot c_{p}^{c} \cdot\left(T_{02}-T_{01}\right)}{\dot{W}_{\text {Tisen }}^{S h}+\dot{W}_{\text {Tisen }}^{H}}
$$

Where, isentropic powers are estimated based on their individual inlet conditions as shown in Equation 14 and 15.

$$
\begin{gathered}
\dot{W}_{\text {Tisen }}^{S h}=\dot{m}_{T}^{S h} \cdot c_{p}^{t, s h} \cdot\left(T_{03}^{S h} \cdot\left(1-\left(1 / \Pi_{t / s}^{S h}\right)^{(\gamma-1 / \gamma)}\right)\right) \\
\dot{W}_{\text {Tisen }}^{H}=\dot{m}_{T}^{H} \cdot c_{p}^{t, h} \cdot\left(T_{03}^{H} \cdot\left(1-\left(1 / \Pi_{t / s}^{H}\right)^{(\gamma-1 / \gamma)}\right)\right)
\end{gathered}
$$

Lastly, Equation 16 shows the typical blade to jet speed ratio (BSR) for both shroud and hub as overall and that can be estimated for different flow 
admission conditions [33].

$$
\sigma_{\text {overall }}=\frac{\pi \cdot D_{t} \cdot N}{\sqrt{2\left(\frac{\dot{W}_{\text {Tisen }}^{\text {Sh }}+\dot{W}_{\text {Tisen }}^{H}}{\dot{m}_{t}^{\text {total }}}\right)}}
$$



Figure 14: Effective turbine efficiency with overall BSR

Figure 14 shows the effective turbine efficiency characteristics by plotting turbine stage efficiency against the overall blade to jet speed ratio for different mass flow ratios that were tested in a gas stand. The resulting turbine efficiency characteristic does not show any convincing information, for further validating models or interpolating between these experimental data, when simulating turbine performance under on engine operative conditions. 


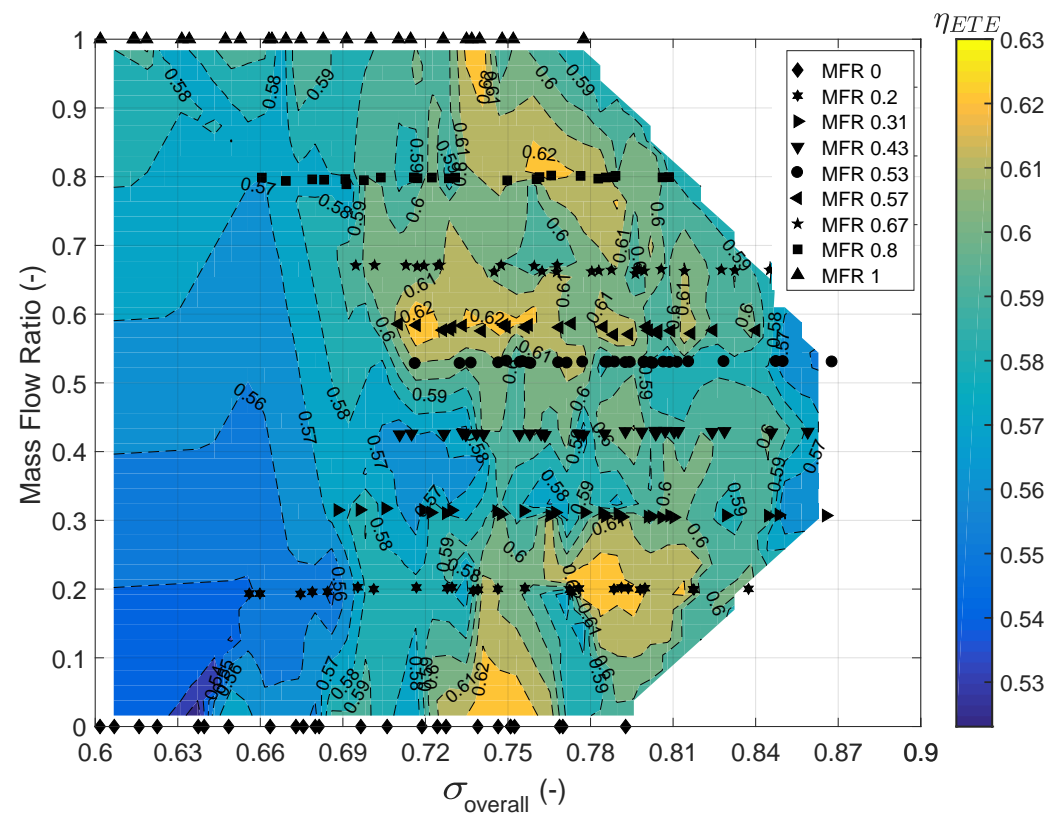

Figure 15: Effective turbine efficiency with overall BSR and MFR (Interpolated)

To better visualize the data, two-dimensional contour plot is preferred as shown in Figure 15. Inside this type of map one can interpolate from the experimental data to show how a dependent variable such as efficiency varies with the mass flow ratios and overall blade to speed ratio. From Figure 15, it can be concluded that the peak efficiencies are mostly found when the turbine is working under unequal admission conditions (i.e. at MFR $0.2,0.6,0.8)$ and in the BSR range between 0.72 and 0.80 according to Equation 16 definition. It is also evident that the overall blade to jet speed ratio is always higher under full and unequal admission conditions than the partial admission, this is due to considering the mass average isentropic power between the two branches shown in Equation 16. Nevertheless, it is clear that for the usability of this information is required and extensive test campaign. 
This is undesirable but true since not a physical model can be extracted from Figure 14 but only interpolating between the efficiency valleys and efficiency peaks as a function of BSR, MFR and maybe also reduced speed. A new approach to analyze these data would be worthy.

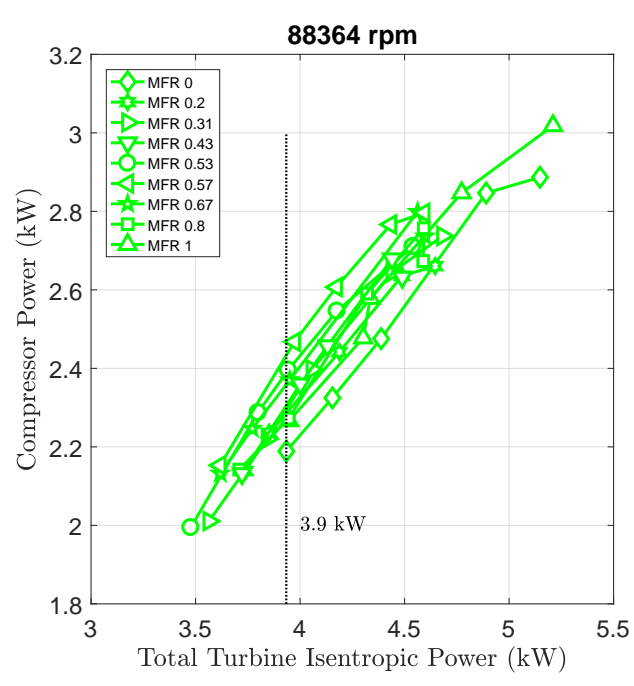

(a) Lower corrected compressor speed

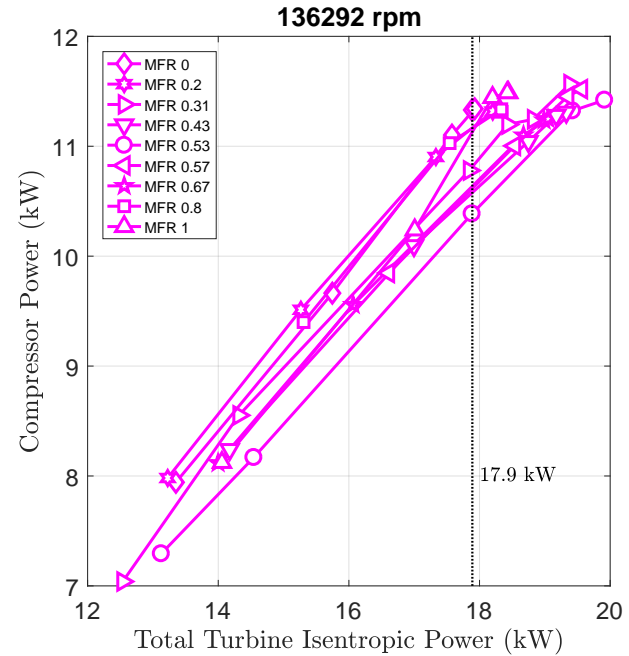

(b) Higher corrected compressor speed

Figure 16: Relation between total isentropic power of turbine with compressor power in different flow admission conditions

Figure 16a and 16b shows in detail results about the relation between total isentropic power of the turbine to compressor power, tested in different mass flow ratios. From both figures, one can perceive that compressor power shows a significant difference for the same isentropic power in the turbine by putting more flow in one branch than the other depending on the turbocharger speed. Figure 16a shows for lower turbocharger speed, and it can be observed that sharing the equal flow in two branches gives better compressor power than at the rest of tested conditions; it is stated by noticing total turbine isentropic 
power of $3.9 \mathrm{~kW}$ (marked in dash lines in Figure 16a) which is mostly similar in different flow admission conditions.

However, as the turbocharger speed increases the trends are changed as shown in Figure 16b, like sharing the flow unequally shows better compressor power than putting the flow equally in both branches; it is stated by observing the total turbine isentropic power of $17.9 \mathrm{~kW}$ (marked in dash lines in Figure 16b) in all the admission conditions. Therefore, not only MFR can be used to decide whether the efficiency would be higher or lower but other parameter must be used. From this, it can be concluded that for high turbocharger speed having the more flow in the hub branch than shroud branch gives better compressor power. Also, analyzing Figure 15 and 16 one can deduce that the global BSR defined in Equation 16 is a key parameter for characterizing global ETE. Much better than reduced speed or MFR, since looks more important for higher ETE being in the right range of BSR (0.72 to 0.8) than at full admission conditions. Being suggested for this type of global efficiency characterization using MFR and BSR as independent variables.

Nevertheless, when the twin entry turbine is working in an engine, the inlet conditions are changed in both branches. By this, we can assume that the power produced by the shroud and hub are different. Consequently, total to static turbocharger turbine efficiencies can be determined for shroud and hub branch independently as shown in equations 17 and 18. The definition of a total to static efficiency for two individual turbines is according to the enthalpy-entropy adiabatic expansion of the turbine shown in Figure 17.

$$
\eta_{t / s}^{S h}=\frac{T_{03}^{S h}-T_{04}^{M F R}}{T_{03}^{S h}-T_{4 s}^{S h}}
$$




$$
\eta_{t / s}^{H}=\frac{T_{03}^{H}-T_{04}^{M F R}}{T_{03}^{H}-T_{4 s}^{H}}
$$

Where isentropic temperatures are estimated individually for shroud and hub as shown in equations 19 and 20

$$
\begin{gathered}
T_{4 s}^{S h}=T_{03}^{S h} \cdot\left(1 / \Pi_{t / s}^{S h}\right)^{(\gamma-1 / \gamma)} ; \\
T_{4 s}^{H}=T_{03}^{H} \cdot\left(1 / \Pi_{t / s}^{H}\right)^{(\gamma-1 / \gamma)}
\end{gathered}
$$

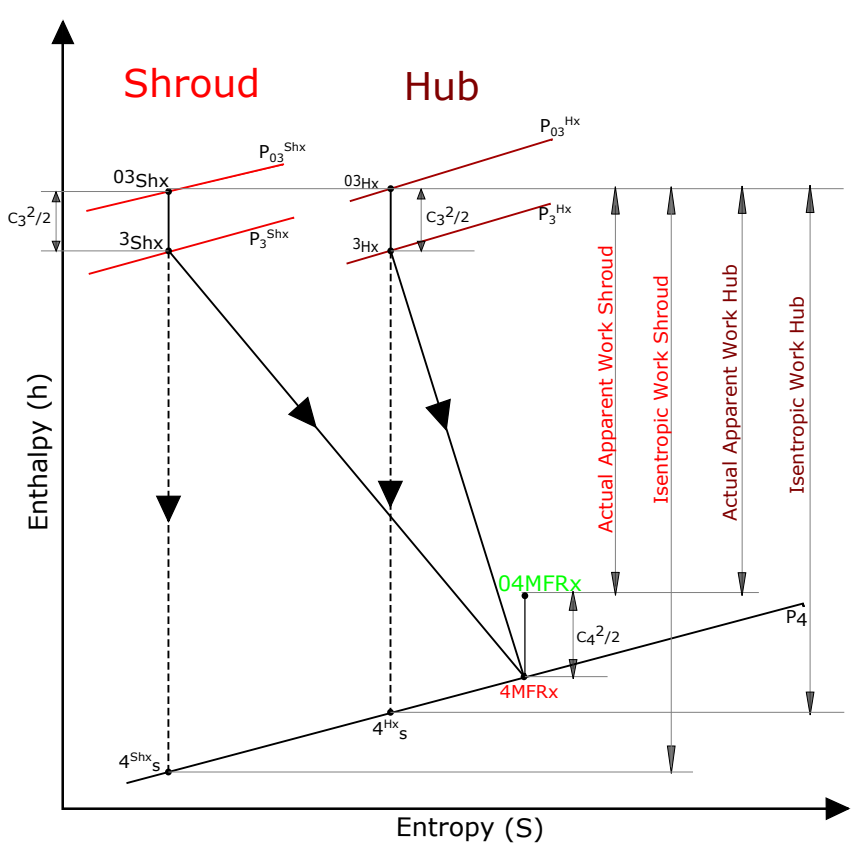

Figure 17: Enthalpy-entropy chart for expansion process

For the accurate calculation of the isentropic efficiencies, the careful determination of the turbine outlet temperature is necessary. It is true that 
measuring the turbine outlet temperature in a gas stand; some difficulty arises due to the complex flows at downstream the turbine. Baar et al. [34], proposed different techniques for obtaining the reliable values of turbine outlet temperature. They compared the isentropic efficiencies calculated using the different approaches, and their results were not conclusive enough to make the statement of using the particular procedure. Though, with a mixing device approach for avoiding the complex flow at the turbine outlet showed the results very close to the SAE standard measurement method [34]. So, it was decided to use four standard $\mathrm{K}$ type thermocouples at the turbine outlet measurement pipe as shown in the Figure 18; and their average values were used for computing the apparent efficiencies. Moreover, the quality of the experiments was assured by checking the energy balance as shown in Figure 9 after the correction of heat transfer and, this shows the measurements are reliable enough.
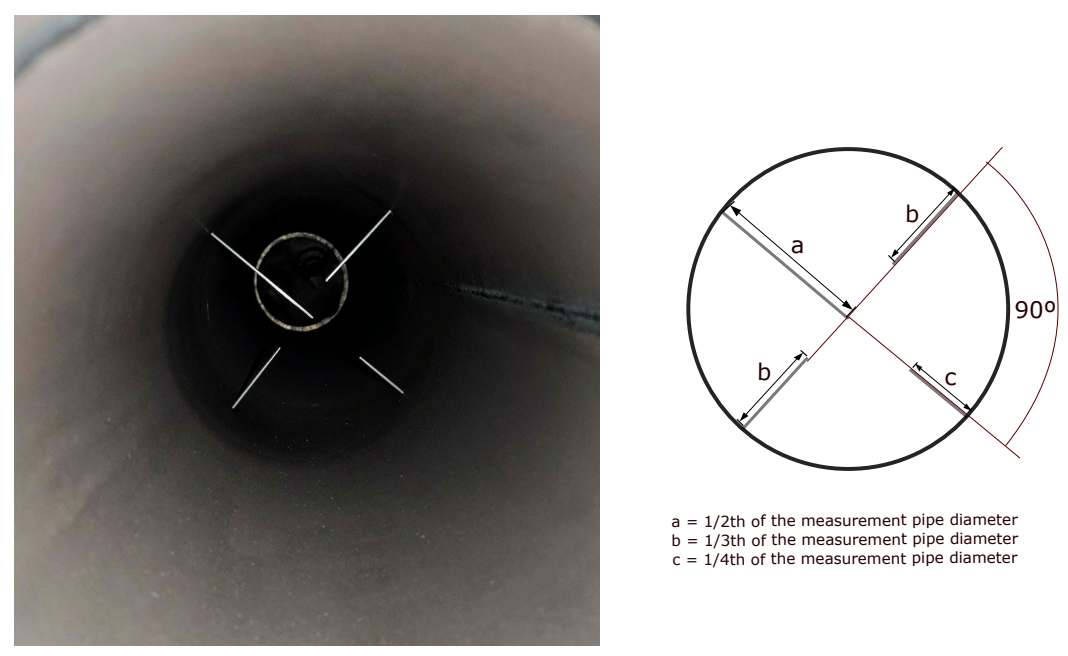

$a=1 / 2$ th of the measurement pipe diameter $b=1 / 3$ th of the measurement pipe diameter
$c=1 / 4$ th of the measurement pipe diameter

Figure 18: K type thermocouples at the turbine outlet measurement pipe 
By considering the two branches as an individual turbine, the available work from each branch is the enthalpy differences between their inlet and outlet conditions of the turbine. Nevertheless, at the outlet of turbine, a mix of temperatures that is coming from the individual branches is the only possible temperature to be measured; even at quasi-adiabatic conditions. Therefore, it is a convenient method to assume the outlet stations in both branches are at equal temperature. Even logic says this fact cannot be true other experimental information is not available; but the average mass temperature of the mix between shroud and hub outlet flows. As a consequence, the efficiency defined from equations 17 and 18 will be called: 'Apparent Efficiency'.

The mechanical efficiency of the twin entry turbine $\left(\eta_{m}^{T W}\right)$ can be calculated as a ratio between the mechanical compressor power to sum of individual turbine branch mechanical power as shown in Equation 21.

$$
\eta_{m}^{T E}=\frac{\dot{m}_{C} \cdot c_{p}^{c} \cdot\left(T_{02}-T_{01}\right)}{\dot{m}_{T}^{S h} \cdot c_{p}^{t, s h} \cdot\left(T_{03}^{S h}-T_{04}^{M F R}\right)+\dot{m}_{T}^{H} \cdot c_{p}^{t, h} \cdot\left(T_{03}^{H}-T_{04}^{M F R}\right)}=\frac{\dot{W}_{C}}{\dot{W}_{T}^{S h}+\dot{W}_{T}^{H}}
$$

This leads to the definition of effective turbine efficiency (ETE) as mentioned before in Equation 13; which can be computed by taking the sum of apparent efficiencies of both branches ponderated with the rate of isentropic power in each branch to total isentropic power $(\beta)$ and doing the product with mechanical efficiency that shown in Equation $21\left(\left(\beta \cdot \eta_{t / s}^{S h}+(1-\beta) \cdot \eta_{t / s}^{H}\right) \eta_{m}^{T W}\right)$. 




Figure 19: Turbine apparent efficiency for Shroud branch

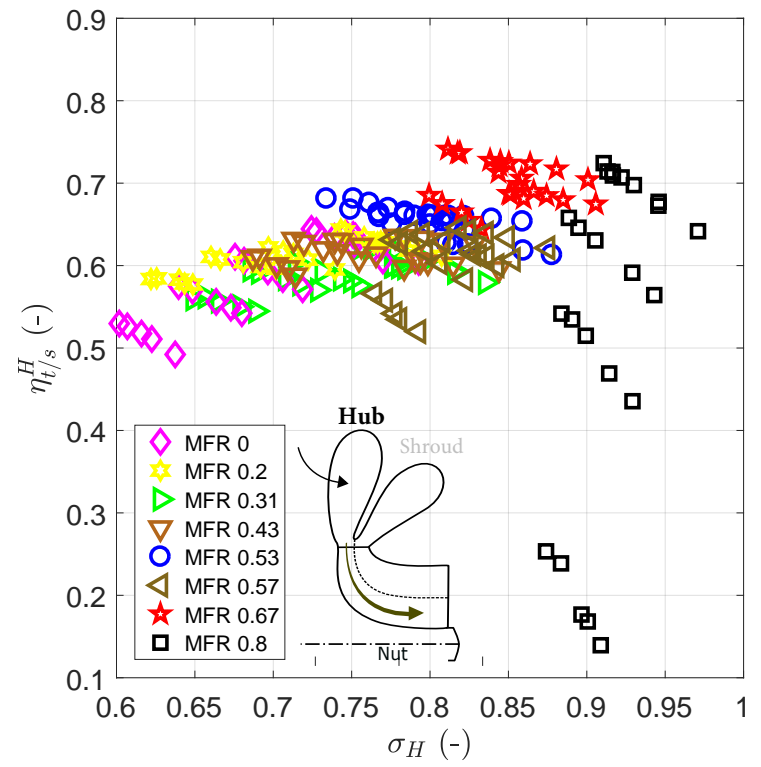

Figure 20: Turbine apparent efficiency for Hub branch 
Figures 19 and 20 show the results of turbine efficiency in various mass flow ratios for shroud and hub branchs. It is clear from these figures that, the major loss of efficiency has taken place when the turbine is working at partial or highly unequal admission conditions ( 0.2 shroud and 0.8 hub). It has been pointed out in the literature to when the flow is mainly or only fed into one entry; the passage feeds entire circumference of the rotor inlet but only half of the span at the leading edge. Therefore, important back flows and mixing losses are generated through the passage up to the trailing edge, as reported previously by Hajilouy-Benisi et al. [18].

Also, both figures show that there are significant differences among isospeeds at Hub and Shroud apparent efficiencies when they are at very low and high MFR numbers; i.e., at MFR=0.2 (yellow points in Shroud branch) and $\mathrm{MFR}=0.8$ (black points in Hub branch) respectively. One can see that $\mathrm{MFR}=0.67$ and 0.8 in hub case and MFR=0.31 and 0.2 in shroud case show the best peak efficiencies. This is due to the apparent efficiency definition, which makes the branches with lower flow to get benefit from the flow expansion (low T4) generated by the branches with higher flow, as shown in Figure 17. The apparent efficiency is good to introduce order in the characterization of the twin entry turbine but doesn't necessary reflects which branch is extracting more efficiently the energy from the flow upstream the turbine. MFR 0.53 shows better apparent efficiency at Hub branch than at Shroud branch (maybe due to less influence of tip leakage losses). One must bear on mind that at MFR $=0.53$ the mass flow is very similar in both branches, so in this case apparent efficiency reflects well the energy extraction of every branch. Therefore, it is here when the twin entry turbine shows 
the highest similarity between Hub and Shroud apparent efficiencies.

As a result, treating shroud and hub separately, we can obtain two different efficiency maps linked to the mass flow parameter maps. Figure 21a and 21b clearly explains the apparent efficiency is dependent on flow conditions in each branch. When the mass flow ratio is at 0.2 , most of the flow is in the Hub branch. In these conditions, the hub efficiency is similar in the tested range of blade to jet speed ratios, with different reduced turbine speeds, and also close to the maximum efficiency. It can also be notable that the efficiency of shroud branch is higher than the hub branch, especially at higher reduced speeds and shows high differences between low and high speeds. Though this is only true as just apparent effects due to very low flow and pressure ratios, most of the flow expansion is produced by hub branch and not by shroud one. The actual efficiency of this branch should be much lower than shown apparent efficiency. However, must be reminded that in the gas stand during the experiments, measuring the turbine outlet temperature from each branch was not possible due to one common outlet branch. 


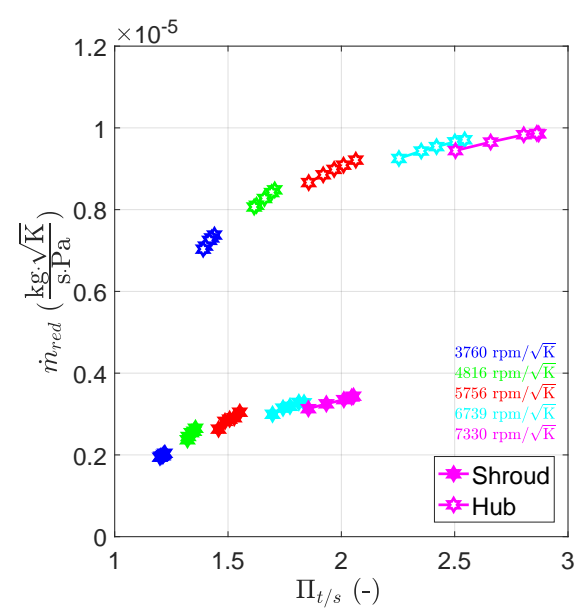

(a) Turbine Map for MFR 0.2

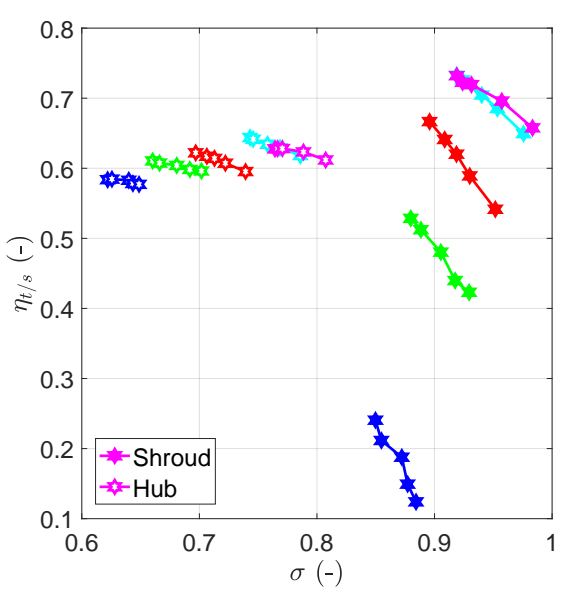

(b) Turbine apparent efficiency for MFR 0.2

Figure 21: Turbine flow and apparent efficiency map in the case of MFR 0.2

Similar results can be found (Figure 22a and 22b) when the turbine is working at mass flow ratio of 0.8 , but inverting shroud by hub situations. In this case, there is more flow in the shroud branch than hub branch.

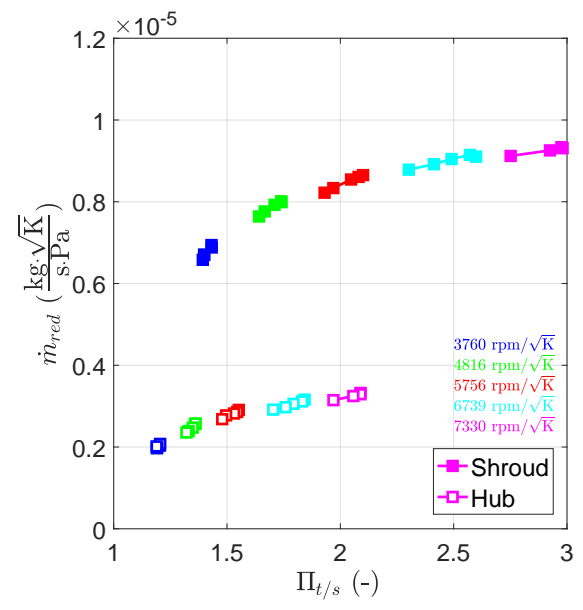

(a) Turbine Map for MFR 0.8

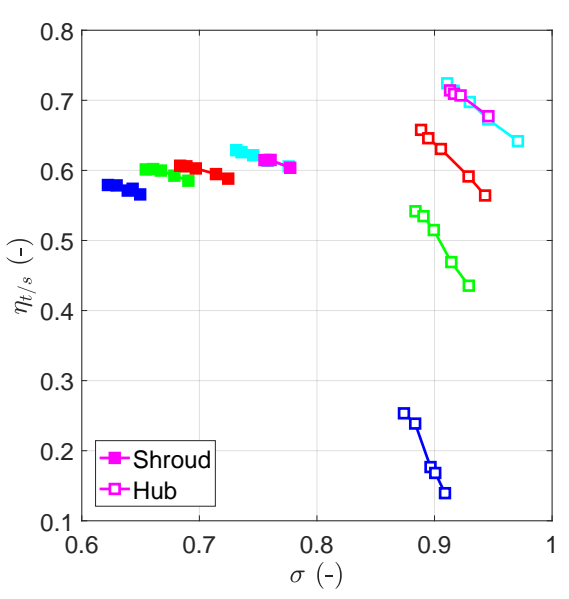

(b) Turbine apparent efficiency for MFR 0.8

Figure 22: Turbine flow and apparent efficiency map in the case of MFR 0.8 


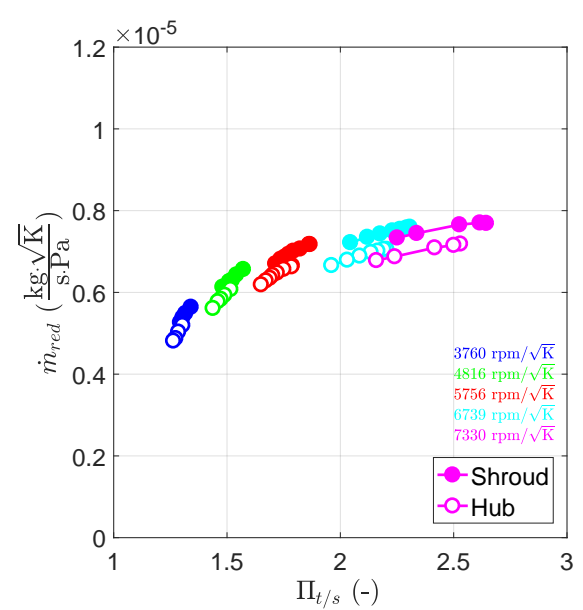

(a) Turbine Map for MFR 0.53

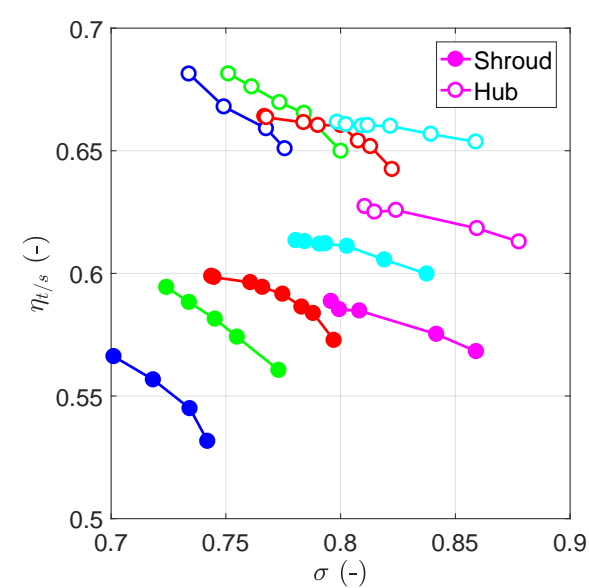

(b) Turbine apparent efficiency for MFR 0.53

Figure 23: Turbine flow and apparent efficiency map in the case of MFR 0.53

Figure 23a and 23b shows the outcomes of experimental results when the turbine is working at almost full admission conditions. Figure 23a indicates that shroud and hub branch have similar flow capacities. Indeed the turbine volutes are symmetrical, and the small difference found in flows and expansion ratios is due to a lack of precision for fitting exactly full admission conditions at gas stand, as mentioned before, and the test were done just closer to MFR 0.5. From Figure 23b it is clear that peak efficiency points for shroud and hub branch are different. Despite having the more flow in Shroud than Hub, the apparent maximum efficiencies are always found when the turbine is working with hub branch for all the reduced speeds. The same can be perceived in cases of unequal admission conditions when there is more flow in the Hub side. A possible explanation can say that having the flow in hub branch; there might be fewer impacts of tip leakage losses as compared to shroud branch. Also one can think that the 'Hub turbine' behaves more 
as a radial in-flow turbine than the 'Shroud turbine'; being able the Hub to extract more work than the Shroud thanks to the higher inlet to outlet radius ratio.

The featured turbine apparent efficiency for two branches confirms that it is dependent on flow conditions in each branch. It appeared that the flow resemblance is well representative with a mass flow ratio. The variation of turbine inlet temperature is also captured by the mass flow ratio. The representation of twin entry characteristic maps of the turbine proposed in this paper would be favorable for current turbocharger models [35] to be fitted and to be able to predict the behavior in off-design conditions. Besides, the usage of this kind of information can anticipate acceptable results in gas dynamic codes.

\section{Summary and Conclusion}

A range of experimental results from a twin entry circumferentially divided turbocharger have been presented in this paper. The turbocharger was tested at different steady flow admission conditions in quasi-adiabatic state. A total of 9- steady flow maps was presented in this work with a different constant mass flow ratio at the turbine inlet. At every mass flow ratio at unequal admission conditions, the amount of mass flow rate going into the two branches, by adding them, is kept quiet similar; which offers interesting insights into the problem. The measurements showed at constant mass flow ratios demonstrate that, contrary to pressure ratio between branches, MFR parameter is sufficient to guarantee constant flow condition along one turbine speed line. Moreover, it is an independent variable of the turbine 
inlet temperature, contrary to Mass flow parameter. What allows keeping the analysis of the variation of turbine inlet temperature depending on flows in each branch, like engine conditions.

The measurements highlighted that considering expansion ratio and turbine scroll inlet temperature as an average value for processing performance data has an impact on resulting maps and difficult to analyze them. In addition, this technique is not transparent under various flow admission conditions. With respect to ETE, calculated by assuming twin turbines as a single turbine, MFR and global BSR have been identified as the main analysis parameters. Even not clear trends have been either show in this global ETE trends, it has been evidenced that being in the right range of BSR $(0,72$ to 0,8$)$ is more important for obtaining higher ETE than being at full admission conditions. This is a novel conclusion since few previous studies have been done keeping total mass flow and turbocharger speed but changing MFR as the studied here discussed.

In spite of previous discussed findings, analysis of the twin entry turbine considered as a single global turbine gives few light to the problem of obtaining meaningful characteristic maps. Therefore, a new methodology for handling the performance maps of twin entry turbine is proposed. The idea is to consider each turbine inlet individually with their respective inlet conditions to calculate the characteristic curves. By this, the importance of flow conditions become clear under different admission situations. Moreover, the flow characteristic maps with the proposed methodology for a different constant mass flow ratio looks very similar to conventional single-entry variable geometry turbine maps. These maps can therefore be extrapolated safely by 
the same procedures as used for the single-entry variable geometry turbine maps.

Accordingly to the proposed methodology, the total-to-static efficiency is estimated for shroud and hub branch independently, by considering respective turbine scroll inlet temperature and the mix of temperatures that is available at the outlet of a turbine. As a result, the obtained apparent efficiency maps can be linked to the mass flow parameter maps. The suggested turbine apparent efficiency for two branches confirms that it is dependent on flow conditions in each branch. Respecting the blade to jet speed ratio for two turbine inlets, enable the plotting of turbine apparent efficiencies with unequal admission conditions and it shows the importance of available energy from each branch. In close to full admission conditions $(\mathrm{MFR}=0.53)$ it has been shown higher efficiency in hub branch. One can think in two hypothesis: the absence of tip leakage losses in the 'Hub turbine' and the higher inlet to outlet radius ratio of 'Hub turbine'; both causes would make able 'Hub turbine' to extract more work than Shroud one. The suggested method makes optimal use of experimental data measured on a gas stand. This gives the advantage to use the current turbine models as two turbines and be able to extrapolate the efficiency maps under off-design conditions. Therefore, and in spite of instantaneous operating conditions for both entries coming from the engine, the characteristic curves proposed in this paper for mimicking allows a given model to be accurate under all extreme circumstances.

The paper further shows a solution for fitting or optimizing reliable onedimensional twin entry turbine models. Just by using the here proposed way of elaborating characteristic twin entry turbine maps. Then, the data in 
these maps can be used as the merit function to predict the behavior of every turbine branch under all tested MFR and BSR conditions. Alternatively, one can use the proposed arrangement for a quasi-steady interpolation of turbine efficiency and mass flow parameter as a function of instantaneous mass flow ratio and expansion ratio or BSR when trying to model a twin or double volute entry turbine.

\section{Acknowledgment}

Vishnu Samala is partially supported through contract FPI-2017-S2-1256 of Programa de Apoyo para la Investigación y Desarrollo (PAID) of Universitat Politècnica de Valéncia. This work was partially funded by FEDER and Government of Spain through Project TRA2016-79185-R. The authors wish to thank M.A. Ortiz and R. Carrascosa for their invaluable work during the experimental setup and campaign.

\section{References}

[1] G. Haq, M. Weiss, CO2 labelling of passenger cars in Europe: Status, challenges, and future prospects, Energy Policy 95 (2016) 324-335. doi:10.1016/j.enpol.2016.04.043.

[2] J. R. Serrano, F. J. Arnau, V. Dolz, P. Piqueras, Methodology for characterization and simulation of turbocharged diesel engines combustion during transient operation. part 1: data acquisition and postprocessing, Applied Thermal Engineering 29 (2009) 142-149. doi:10. 1016/j . applthermaleng. 2008.02.011. 
[3] A. Broatch, J. R. Serrano, F. J. Arnau, D. Moya, Time-domain computation of muffler frequency response: comparison of different numerical schemes, Journal of Sound and Vibration 305 (2007) 333-347. doi:10.1016/j.jsv.2007.04.023.

[4] G. Kalghatgi, Is it really the end of internal combustion engines and petroleum in transport?, Applied Energy 225 (2018) 965-974. doi:10. 1016/j. apenergy. 2018.05.076.

[5] M. Romare, L. Dahllöf, The life cycle energy consumption and greenhouse gas emissions from lithium-ion batteries, IVL Swedish Environmental Research Institute (2017) 8-42. doi:978-91-88319-60-9.

[6] J. R. Serrano, Imagining the future of the internal combustion engine for ground transport in the current context, Applied Sciences 7 (2017) 1001. doi:10.3390/app7101001.

[7] J. Heywood, D. MacKenzie, I. B. Akerlind, P. Bastani, I. Berry, K. Bhatt, S. Zoepf, On the road toward 2050: Potential for substantial reductions in light-duty vehicle energy use and greenhouse gas emissions, 2015. URL: http://web.mit.edu/sloan-auto-lab/reasearch/ beforeh2/otr2050/.

[8] R. W. Kruiswyk, The role of turbocompound in the era of emissions reduction., 10th International Conference on Turbochargers and Turbocharging (2012) 269-280. doi:10.1533/9780857096135.5.269.

[9] D. Zhu, X. Zheng, Asymmetric twin-scroll turbocharging in diesel en- 
gines for energy and emission improvement, Energy 141 (2017) 702-714. doi:10.1016/j.energy .2017.07.173.

[10] N. Watson, Turbocharging the internal combustion engine, Macmillan, 1982. doi:10.1007/978-1-349-04024-7.

[11] M. Cerdoun, A. Ghenaiet, Characterization of a twin-entry radial turbine under pulsatile flow condition, International Journal of Rotating Machinery (2016). doi:10.1155/2016/4618298.

[12] N. Winkler, H.-E. Ångström, U. Olofsson, Instantaneous On-Engine Twin-Entry Turbine Efficiency Calculations on a Diesel Engine (2005). doi:10.4271/2005-01-3887.

[13] F. Pischinger, A. Wunsche, The characteristic behaviour of radial turbines and its influence on the turbocharging process, in: Proceedings of the CIMAC Conference, Tokyo, Japan, 1977.

[14] A. Dale, N. Watson, Vaneless radial turbocharger turbine performance, in: Proceedings of the IMechE, 1986, pp. 65-76. C110/86.

[15] M. Capobianco, A. Gambarotta, Performance of a twin-entry automotive turbocharger turbine, in: ASME Energy-Sources Technology Conference and Exhibition, Houston, 1993. Paper 93-ICE-2.

[16] N. C. Baines, M. Lavy, Flows in vaned and vaneless stators of radial inflow turbocharger turbines, in: IMechE turbocharging and turbochargers conference, London, UK, 1990, pp. 7-12. Pap. No. C405/005. 
[17] N. C. Baines, A. Hajilouy-Benisi, J. H. Yeo, The pulse flow performance and modelling of radial-inflow turbines, in: Proceedings IMechE international conference turbochargers turbocharging, London, UK, 1994, p. 209-219.

[18] A. Hajilouy-Benisi, M. Rad, M. R. Shahhosseini, Flow and performance characteristics of twin-entry radial turbine under full and extreme partial admission conditions, Archive of Applied Mechanics 79 (2009) 1127-1143. doi:10.1007/s00419-008-0295-5.

[19] A. Romagnoli, R. F. Martinez-Botas, S. Rajoo, Steady state performance evaluation of variable geometry twin-entry turbine, International Journal of Heat and Fluid Flow 32 (2011) 477-489. doi:10.1016/j. ijheatfluidflow.2010.12.002.

[20] S. Rajoo, A. Romagnoli, R. F. Martinez-Botas, Unsteady performance analysis of a twin-entry variable geometry turbocharger turbine, Energy 38 (2012) 176-189. doi:10.1016/j . energy .2011.12.017.

[21] M. S. Chiong, S. Rajoo, A. Ramagnoli, A. W. Costall, R. F. MartinezBotas, One-dimensional pulse-flow modeling of a twin-scroll turbine, Energy 115 (2016) 1291-304. doi:10.1016/j .energy . 2016 .09.041.

[22] Supercharger Testing Standard, SAE J1723, Society of Automotive Engineers, 1995.

[23] Turbocharger Gas Stand Test Code, SAE J1826, Society of Automotive Engineers, 1995. 
[24] N. Brinkert, S. Sumser, S. Weber, K. Fieweger, A. Schulz, H.-J. Bauer, Understanding the Twin Scroll Turbine: Flow Similarity, Journal of Turbomachinery 135 (2012). doi:10.1115/1.4006607.

[25] N. Cavina, A. Borelli, L. Calogero, R. e. a. Cevolani, Turbocharger Control-Oriented Modeling: Twin-Entry Turbine Issues and Possible Solutions, SAE Int. J. Engines 8 (2015). doi:10.4271/2015-24-2427.

[26] D. Lückmann, M. Stadermann, S. Pischinger, H. Kindl, Advanced Measurement and Modelling Methods of turbochargers, MTZ worlwide 77 (2016) 80-87. doi:10.1007/s38313-016-0055-9.

[27] R. Zimmermann, R. Baar, C. Biet, Determination of the isentropic turbine efficiency due to adiabatic measurements and the validation of the conditions via a new criterion, in: Proceedings of the Institution of Mechanical Engineer Part C: Journal of Mechanical Engineering Science, 2016, p. 1-10. doi:10.1177/0954406216670683.

[28] Evaluation of measurement data - Guide to the expression of uncertainty in measurement, JCGM 100:2008, Joint Comittee for Guides in Metrology, 2008.

[29] P. Olmeda, A. Tiseira, V. Dolz, L. M. García-Cuevas, Uncertainties in power computations in a turbocharger test bench, Measurement 59 (2015) 363 - 371. doi:10.1016/j .measurement.2014.09.055.

[30] A. Romagnoli, C. D. Copeland, R. F. Martinez-Botas, M. Seiler, S. Rajoo, A. Costall, Comparison Between the Steady Performance of Double- 
Entry and Twin-Entry Turbocharger Turbines, Journal of Turbomachinery 135 (2012). doi:10.1115/1.4006566.

[31] D. Japikse, N. C. Baines, Introduction to turbomachinery, Concepts ETI, Inc. and Oxford University Press, 1997.

[32] J. R. Serrano, A. Tiseira, L. M. García-Cuevas, L. B. Inhestern, H. Tartoussi, Radial turbine performance measurement under extreme offdesign conditions, Energy 125 (2017) 72-84. doi:10.1016/j.energy. 2017.02 .118$.

[33] H. Mai, A. Kaufmann, Methodology to Evaluate the Characteristics of a Twin-scroll Turbocharger with Various Approaches for the Computation of Thermodynamic Properties, in: Turbo Expo: Power for Land, Sea, and Air, ASME, 2017. doi:10.1115/GT2017-63462, Volume 8: Microturbines, Turbochargers and Small Turbomachines; Steam Turbines: V008T26A007.

[34] R. Baar, C. Biet, V. Boxberger, H. Mai, R. Zimmermann, New evaluation of turbocharger components based on turbine outlet temperature measurements in adiabatic conditions, in: 15th international symposium on transport phenomena and dynamics of rotating machinery, ISROMAC-15, Honolulu, USA, 2014.

[35] J. R. Serrano, F. J. Arnau, L. M. García-Cuevas, A. Dombrovsky, H. Tartoussi, Development and validation of a radial turbine efficiency and mass flow model at design and off-design conditions, Energy Con- 
version and Management 128 (2016). doi:10.1016/j.enconman.2016. 09.032 . 